The Canadian Mineralogist

Vol. 43, pp. 1895-1920 (2005)

\title{
SHORT-RANGE ORDER IN MINERALS: AMPHIBOLES
}

\author{
FRANK C. HAWTHORNE $\$$ \\ Department of Geological Sciences, University of Manitoba, Winnipeg, Manitoba R3T 2N2, Canada \\ GIANCARLO DELLA VENTURA \\ Dipartimento di Scienze Geologiche, Universitá di Roma Tre, Largo San Leonardo Murialdo 1, I-00146 Roma, Italy \\ ROBERTA OBERTI \\ CNR-Istituto di Geoscienze e Georisorse, sezione di Pavia, via Ferrata 1, I-27100 Pavia, Italy \\ JEAN-LOUIS ROBERT \\ ISTO, UMR 6113, 1A Rue de la Ferollerie, F-45071 Orléans Cedex 2, France \\ GIANLUCA IEZZI \\ Dipartimento di Scienze della Terra, Universitá G.D’Annunzio, via dei Vestini 30, I-66100 Chieti Scalo, Italy
}

\begin{abstract}
Short-range order involves local clusters of atoms that occur either more or less frequently than predicted by a random distribution. Infrared spectroscopy in the principal $(\mathrm{OH})$-stretching region is sensitive to such local arrangements, and hence the $(\mathrm{OH})$ group can be used as a local probe of short-range arrangements of atoms. Examination of natural amphiboles of fairly simple composition indicates that the principal $(\mathrm{OH})$-stretching frequency is sensitive to such local arrangements, generating fine structure that gives information on short-range arrangements. Moreover, the fine structure is sensitive to both nearest-neighbor and next-nearest-neighbor arrangements. The short-range arrangements that can occur are constrained by the local version of the valence-matching principle, and this helps in assignment of the bands in the fine structure of the corresponding infrared spectra. Recent results on synthetic amphiboles illustrate these issues. Monoclinic amphiboles in the systems richterite-pargasite, tremolite-pargasite and tremolite-hornblende show strong SRO involving $T$-, $C$ - and $A$-group cations. Amphiboles involving $(\mathrm{OH})-\mathrm{F}$ solid-solution with $\square$ (vacancy) at the $A$ site (e.g., tremolite-fluorotremolite) show one-mode behavior, whereas amphiboles with $\mathrm{Na}$ or $\mathrm{K}$ at the $A$ site (e.g., richterite-fluororichterite) show two-mode behavior, indicating that nearest-neighbor arrangements of atoms couple through an occupied $A$ site, but do not couple through a vacant $A$ site. Furthermore, the relative band intensities in $(\mathrm{OH})-\mathrm{F}$ amphibole solid-solutions showing two-mode behavior indicate that $(\mathrm{OH})$ and $\mathrm{F}$ are completely short-range disordered with respect to each other in the amphibole series examined thus far. Amphiboles in the system pargasite-fluoropargasite show strong SRO of $(\mathrm{OH})$ and $\mathrm{F}$ with regard to the cations occupying the associated nearest-neighbor $M(1) M(1) M(3)$ sites: arrangements involving MgMgAl- $(\mathrm{OH})$ are far more common than arrangements involving MgMgAl-F. Examination of Ti-bearing richteritic amphiboles show that ${ }^{[4]} \mathrm{Ti}^{4+}$ and $\mathrm{Si}$ are short-range disordered with regard to each other. Crystal-structure refinement, SIMS analysis and local bond-valence requirements suggest that ${ }^{[6]} \mathrm{Ti}^{4+}$ and ${ }^{\mathrm{O}(3)} \mathrm{O}^{2-}$ are locally associated at adjacent $M(1)$ and $\mathrm{O}(3)$ sites in (at least some) amphiboles. It is apparent that SRO is very common in monoclinic amphiboles. Although much work remains to be done to fully characterize SRO in amphiboles, the general features are already emerging, and local bond-valence requirements seem to be the (principal) factor controlling this type of order. SRO is of significance in that it will affect the stability of amphiboles (and other minerals in which it occurs) through its entropy (and enthalpy) effects; the way in which these effects can be formulated for such a complicated case is not yet clear, but what is clear is that future thermodynamic models need to consider SRO in amphiboles and probably in other minerals in which heterovalent substitutions are common.
\end{abstract}

Keywords: short-range order, amphiboles, infrared spectroscopy, local bond-valence requirements, tremolite, richterite, pargasite.

$\S$ E-mail address: frank_hawthorne@umanitoba.ca 


\section{SOMMAIRE}

Une mise en ordre locale implique des groupements locaux d'atomes avec une fréquence plus ou moins grande que ce qui est prédit selon une distribution aléatoire. La spectroscopie infrarouge dans la région principale des étirements $(\mathrm{OH})$ est sensible à de tels arrangements locaux, et les groupes $(\mathrm{OH})$ peuvent donc servir d'indicateur de la mise en ordre à l'échelle locale. Un examen des amphiboles naturelles de composition relativement simple indique que la région des étirements des groupes $(\mathrm{OH})$ est sensible à de tels arrangements, et fait preuve de structure fine pouvant donner de l'information au sujet des agencements à courte échelle. De plus, la structure fine est sensible aux agencements impliquant les voisins immédiats et les deuxièmes voisins. Les agencements possibles doivent répondre aux exigeances locales du principe de la concordance des valences, ce qui aide dans l'assignation des bandes dans la structure fine du spectre infrarouge correspondant. Les résultats acquis récemment pour les amphiboles synthétiques illustrent ces problèmes. Les amphiboles monocliniques des systèmes richtérite-pargasite, trémolite-pargasite et trémolite-hornblende font preuve de mise en ordre importante à courte échelle impliquant les groupes de cations $T, C$ et $A$. Les amphiboles montrant une solution solide impliquant le couple $(\mathrm{OH})-\mathrm{F}$ et une lacume au site $A(e . g$., trémolite-fluorotrémolite) font preuve d'un comportement unimodal, tandis que les amphiboles ayant $\mathrm{Na}$ ou $\mathrm{K}$ au site $A$ (e.g., richtérite-fluororichtérite) possèdent un comportement bimodal, indication que les agencements des deuxièmes voisins deviennent couplés via le site $A$ occupé, mais ne le deviennent pas où le site $A$ est vacant. De plus, les intensités relatives des bandes de telles amphiboles à comportement bimodal montrent que le $(\mathrm{OH})$ et le $\mathrm{F}$ sont complètement désordonnés à courte échelle par rapport l'un à l'autre dans les séries examinées jusqu'à date. Les amphiboles du système pargasite-fluoropargasite font preuve d'un désordre marqué de $(\mathrm{OH})$ et $\mathrm{F}$ par rapport aux cations occupant les sites $M(1) M(1) M(3)$ de type "deuxièmes voisins" associés. Les agencements impliquant $\mathrm{MgMgAl}-(\mathrm{OH})$ sont beaucoup plus courants que les agencements $\mathrm{MgMgAl}-\mathrm{F}$. Une étude des amphiboles richtéritiques montre que ${ }^{[4]} \mathrm{Ti}^{4+}$ et $\mathrm{Si}$ sont désordonnés à courte échelle par rapport l'un à l'autre. D'après les affinements des structures, les résultats d'analyses par sonde ionique et les exigeances des valences de liaison, ${ }^{[6]} \mathrm{Ti}^{4+}{ }^{4+}{ }^{\mathrm{O}(3)} \mathrm{O}^{2-}$ sont localement associées sur les sites $M(1)$ et $\mathrm{O}(3)$ adjacents dans au moins certaines amphiboles. La mise en ordre à courte échelle serait très répandue dans les amhiboles monocliniques. Quoiqu'il reste beaucoup à faire pour caractériser complètement ce type de mise en ordre dans les amphiboles, les grandes lignes sont déjà établies, et les exigeances locales des valences de liaison semblent être le facteur principal régissant le phénomène. Cette mise en ordre locale serait importante à cause de son rôle dans la stabilité des amphiboles et des autres minéraux concernés, grâce aux répercussions sur l'entropie (et l'enthalpie). La façon de formuler de tels effets dans un tel cas compliqué n'est pas encore claire, mais il est d'ores et déjà évident que les modèles thermodynamiques futurs devront prendre en considération la mise en ordre locale des amphiboles et probablement des autres minéraux dans lesquels les substitutions hétérovalentes sont répandues.

(Traduit par la Rédaction)

Mots-clés: mise en ordre locale, amphiboles, spectroscopie infrarouge, exigeances locales des valences de liaisons, trémolite, richtérite, pargasite.

\section{INTRODUCTION}

In the past thirty years, there has been an enormous amount of work on long-range order (LRO) of atoms in common rock-forming minerals. This has been accompanied by investigations into the relations among mineral composition, structural state, physical properties and ambient conditions of crystallization or equilibration. The experimental techniques by which this work is done have seen considerable development over this time, and both diffraction and spectroscopic methods are now capable of producing results of high precision and considerable accuracy. However, LRO is only one type of atomic-scale order that occurs in minerals; short-range order (SRO) also can occur. The problem is that SRO does not obey the translational symmetry of the structure in which it occurs, and hence SRO is difficult to detect and decipher directly by standard diffraction methods. There is information on SRO resident in diffuse scattering from a crystal, but this information is quite difficult to extract, particularly where the SRO is complicated, and this approach has only been used for simpler materials. SRO can be detected by several spectroscopic techniques [e.g., infrared spectroscopy, magic-angle-spinning nuclear magnetic resonance (MAS NMR) spectroscopy], but the problem is that only part of the local arrangement is derived, and the complete picture of SRO is commonly not clear. Here, we shall examine the issue of SRO of cations and anions in monoclinic amphiboles, and show that detailed information on SRO can be derived by a combination of infrared spectroscopy and local bondvalence theory, augmented by results from Rietveld and single-crystal diffraction. Ionic radii are taken from Shannon (1976), and bond-valence curves are taken from Brown \& Altermatt (1985).

\section{LONG-RANGE ORDER}

Let us first examine the issue of LRO for a simple (two-dimensional) crystal of general composition $M_{2} \mathrm{SiO}_{4}$, where $M=\mathrm{Mg}, \mathrm{Fe}^{2+}$, and consider the composition $\mathrm{Mg}_{0.8} \mathrm{Fe}^{2+}{ }_{1.2} \mathrm{SiO}_{4}$ for the case where there are two distinct sites, $M(1)$ and $M(2)$, in the unit cell (Fig. 1). Maximum order involves complete occupancy of one site by $\mathrm{Fe}^{2+}$ and occupancy of the other site by a mixture of $\mathrm{Mg}$ and $\mathrm{Fe}^{2+}$. Either $M(1)$ or $M(2)$ can be fully occupied by $\mathrm{Fe}^{2+}$, leading to the two long-range 
ordered arrangements shown in green in Figure 1. Long-range disorder occurs where $\mathrm{Mg}$ and $\mathrm{Fe}^{2+}$ occur in equal amounts at the $M(1)$ and $M(2)$ sites, shown in pink in Figure 1. As indicated above, the states of order shown in Figure 1, and any states intermediate between them, can be easily determined by various diffraction and spectroscopic techniques.

\section{SHORT-RANGE ORDER}

Let us now examine the issue of SRO for the same (two-dimensional) crystal shown in Figure 1. LRO involves the occupancies of the sites averaged over the complete crystal, whereas SRO involves the occupancy of individual (i.e., non-averaged) sites over a scale of a few $\AA$. This situation is illustrated in Figure 2 by a few unit cells of the crystal. The $M(1)$ site in the central unit cell is surrounded by four other sites, two $M(1)$ sites and two $M(2)$ sites. SRO involves the formation of local clusters of atoms that occur either more or less than predicted by a random distribution, and of course there is no LRO as we are only dealing with a nonperiodic cluster of atoms. The four nearest-neighbor $M$ sites surrounding the central $M(1)$ site (Fig. 2) may be occupied by $\mathrm{Fe}^{2+}{ }_{4}, \mathrm{Fe}^{2+}{ }_{3} \mathrm{Mg}, \mathrm{Fe}^{2+}{ }_{2} \mathrm{Mg}_{2}, \mathrm{Fe}^{2+} \mathrm{Mg}_{3}$, or $\mathrm{Mg}_{4}$. For a crystal of composition $\mathrm{Mg}_{0.8} \mathrm{Fe}^{2+}{ }_{1.2} \mathrm{SiO}_{4}$, a random distribution of nearest-neighbor cations will give the frequencies of occurrence of the possible clusters indicated in Figure 2. On the other hand, the local distribution may not be random (i.e., disordered); it may be ordered, whereby some clusters occur to a greater extent than a random distribution indicates, and other clusters occur to a correspondingly more limited extent than a random distribution indicates. Figure 2 shows an SRO arrangement in which the cluster $\mathrm{Mg}_{4}$ occurs much more, and the cluster $\mathrm{Fe}^{2+}{ }_{2} \mathrm{Mg}_{2}$ occurs much less commonly, if compared with a random distribution. For the short-range disordered model, the frequency of occurrence of each arrangement is calculated as the product of the fraction of each component, weighted according to the number of times it occurs in the arrangement; the resultant values are then normalized to unity. Thus for the example in Figure 2, the relative frequencies of occurrence are $0.6^{4}, 0.6^{3} \times 0.4,0.6^{2} \times$ $0.4^{2}, 0.6 \times 0.4^{3}$ and $0.4^{4}$; these values normalize to those given in Figure 2. For short-range order, there are several different end-member arrangements compatible with the bulk composition of the crystal in Figure 2, e.g., (1) $\mathrm{Fe}_{4} 0.6, \mathrm{Mg}_{4}$ 0.4, others zero; (2) $\mathrm{Fe}_{4} 0.2, \mathrm{Fe}_{2}$ $\mathrm{Mg}_{2}$ 0.8, others zero. The frequencies of occurrence for short-range order shown in Figure 2 are examples of a partial degree of SRO involving the occurrence of all arrangements (that are compatible with the bulk composition of the crystal).

The above discussion involves SRO of homovalent cations. Of more interest from a crystal-chemical and mineralogical perspective is SRO involving heterovalent cations (or anions), as these states of order involve much greater changes in local bond-valence distribution than do changes in states of SRO involving homovalent cations (Hawthorne 1997). In turn, the resultant bondvalence constraints on local arrangements may have significant effects on the variation of chemical composition and stability of the constituent minerals.

It should also be emphasized that data on SRO are not easily obtained. No single experimental method is the philosophers' stone for this information. In principle, diffraction techniques do give information on $\mathrm{SRO}$ in diffuse scattered intensity. However, in practice, this information is difficult to extract, even for simple minerals, let alone for the more complex rock-forming silicate minerals. Several spectroscopic techniques are sensitive to states of local order, but all have only limited application in complex solids. As shown below, infrared spectroscopy can be used to characterize SRO in $(\mathrm{OH})$-bearing minerals such as amphiboles or micas, where the sensitivity of the $\mathrm{O}-\mathrm{H}$ stretching frequency (energy) to local environment can be exploited. However, in the absence of $\mathrm{OH}$, infrared spectroscopy is of little use for characterizing SRO in complicated minerals. Also, the $\mathrm{O}-\mathrm{H}$ stretching frequency is sensitive to local order involving NN (nearest-neighbor) cations, but is less sensitive to cation arrangements further away from the $(\mathrm{OH})$ group involved. Another technique of considerable use is MAS NMR (MagicAngle Spinning - Nuclear Magnetic Resonance), which can sense different arrangements of NNN (next-nearestneighbor) cations of sensitive nuclei in diamagnetic materials [the presence of even minor $(\sim 2 \%) \mathrm{Fe}^{2+}$ paramagnetic constituents can quench the signal]. However, the importance of aluminosilicate minerals from a geological perspective somewhat offsets this constraint on its use.

Given that short-range order-disorder is quite difficult to characterize from an experimental perspective, why should one be interested in it? The interest in SRO arises because it affects the stability of a mineral in the same way as LRO, through its associated configurational entropy and enthalpy of order-disorder, and it will also affect the exchange of elements between coexisting minerals.

\section{LRO IN MONOCLINIC AMPHIBOLES}

The general formula of the amphiboles may be written as

$$
A B_{2} C_{5} T_{8} \mathrm{O}_{22} W_{2}
$$

where $A=\square, \mathrm{Na}, \mathrm{K}, \mathrm{Ca} ; B=\mathrm{Ca}, \mathrm{Mn}^{2+}, \mathrm{Fe}^{2+}, \mathrm{Mg}, \mathrm{Na}$, $\mathrm{Li} ; C=\mathrm{Mg}, \mathrm{Fe}^{2+}, \mathrm{Mn}^{2+}, \mathrm{Al}, \mathrm{Fe}^{3+}, \mathrm{Ti}^{4+}, \mathrm{Li} ; T=\mathrm{Si}, \mathrm{Al}$, $\mathrm{Ti}^{4+}$, and $W=(\mathrm{OH}), \mathrm{F}, \mathrm{Cl}, \mathrm{O}^{2-}$.

The list of elements given above is by no means comprehensive, but does incorporate the more common constituents of the amphibole structure. Most amphiboles adopt the monoclinic $C 2 / \mathrm{m}$ structure; this struc- 


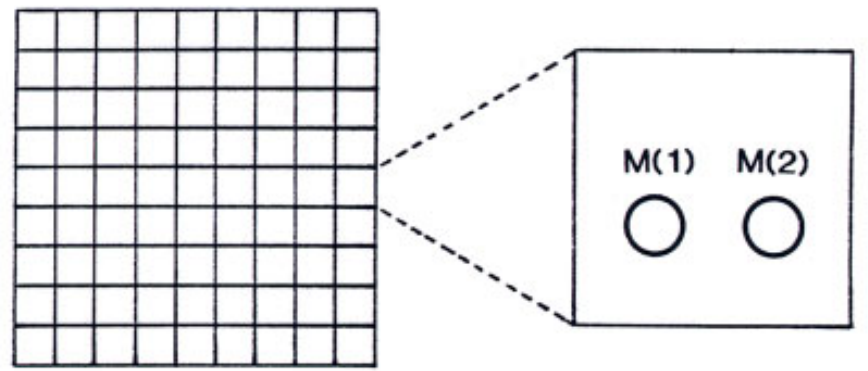

\section{POSSIBLE ORDERING SCHEMES FOR A CRYSTAL OF COMPOSITION Fe ${ }_{1.2}^{2+} \mathrm{Mg}_{0.8} \mathrm{SiO}_{4}$}

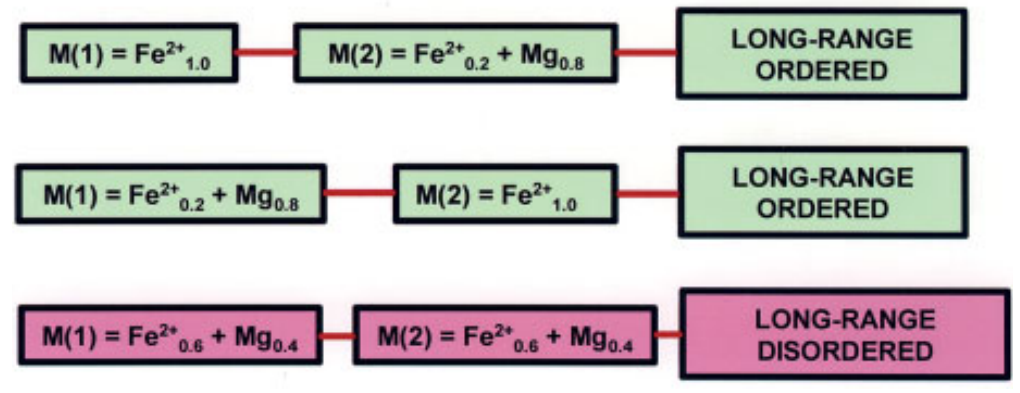

FIG. 1. Sketch of a symbolic (two-dimensional) crystal structure showing a series of unit cells containing two cation sites, $M(1)$ and $M(2)$, together with long-range ordered and long-range disordered site-populations for a bulk composition $\mathrm{Mg}_{0.8} \mathrm{Fe}^{2+}{ }_{1.2} \mathrm{SiO}_{4}$.

\section{SHORT-RANGE ORDER / DISORDER : $\mathrm{Fe}^{2+}{ }_{1.2} \mathrm{Mg}_{0.8} \mathrm{SiO}_{4}$}

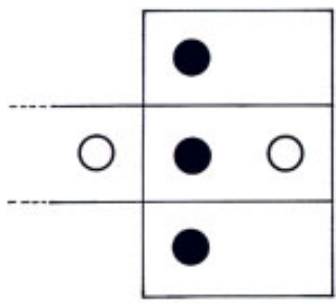

SHORT-RANGE DISORDERED
M(1) FIG. 2. Sketch of a four unit-cell fragment of the symbolic structure of Fig. 1, showing the local (next-nearest neighbor) environment around one $M(1)$ site, together with short-range ordered and short-range disordered arrangements for a bulk composition $\mathrm{Mg}_{0.8} \mathrm{Fe}^{2+}{ }_{1.2} \mathrm{SiO}_{4}$.

$\mathrm{Fe}_{4}$ 0.38

0.26

0.17

$\mathrm{Fe}_{2}$

$\mathrm{FeMg}_{3}$

0.11

$M(2)$

\section{HORT-
RDER}

\section{RANGE ORDER}

$\mathrm{Mg}_{4}$

0.08 
ture is illustrated in Figure 3, which can be used to follow the ensuing discussions involving nearest- and next-nearest-neighbor polyhedra.

Before we can begin to examine SRO in amphiboles, we need to understand the behavior of atoms involved in LRO, as LRO gives us information on what types of short-range arrangements are not possible just because atoms do not occupy those specific sites.

The $T$-group cations occupy the $T(1)$ and $T(2)$ sites (Fig. 3). Crystal-structure refinement has shown that Al is strongly ordered at the $T(1)$ site (Papike et al. 1969, Robinson et al. 1973, Hawthorne \& Grundy 1973a, b, Bocchio et al. 1978, Hawthorne 1983, Oberti et al. 1995a). However, small amounts of Al can occur at the T(2) site, and Oberti et al. (1995a) showed that the amounts of disorder of $\mathrm{Al}$ between $T(1)$ and $T(2)$ is a function of temperature of crystallization. Oberti et al. (1992) showed that ${ }^{[4]} \mathrm{Ti}$ is completely ordered at the $T(2)$ site in richteritic amphiboles.

The $C$-group cations occupy the $M(1), M(2)$ and $M(3)$ sites of the octahedron strip (Fig. 3), and within these sites, there can be strong LRO of cations. The most common cations in this group are $\mathrm{Mg}$ and $\mathrm{Fe}^{2+}$, and these can show complete solid-solution at all three sites. Trivalent cations $\mathrm{Al}$ and $\mathrm{Fe}^{3+}$ generally occur at the $M(2)$ site (Hawthorne 1983), although significant disorder of $\mathrm{Al}$ over $M(2)$ and $M(3)$ occurs in $\mathrm{Mg}$-rich pargasite (Oberti et al. 1995b), and $\mathrm{Fe}^{3+}$ can occur at $M(1)$ and $M(3)$, particularly where associated with oxidation-dehydroxylation (e.g., Ernst \& Wai 1970, Phillips et al. 1988, 1989). Where present in significant amounts (>0 0.2 apfu: atoms per formula unit), ${ }^{[6]} \mathrm{Ti}$ occurs primarily at $M(1)$ (Kitamura et al. 1973, 1975, Oberti et al. 1992, Hawthorne et al. 1998, Tiepolo et al . 1999), entering via the oxy substitution $\mathrm{Ti}^{4+}+2 \mathrm{O}^{2-} \rightarrow$ $\left(\mathrm{Mg}, \mathrm{Fe}^{2+}\right)+2(\mathrm{OH})$. Where present in small amounts $(<0.20$ atoms per formula unit, $a p f u)$, the behavior of ${ }^{[6]} \mathrm{Ti}$ is not easy to characterize; early work assigned ${ }^{[6]} \mathrm{Ti}$ present in small amounts solely to the $M(2)$ site, but there is no experimental justification for this assignment. $C$-group $\mathrm{Li}$ is always completely ordered at the M(3) site (Hawthorne et al. 1992, 1993, 1994, 1996b, Armbruster et al. 1993, Oberti et al. 2003, Tait et al. 2004). This strong ordering of non-divalent cations results in strong differential occupancy of the $M(1,2,3)$ sites by $\mathrm{Mg}$ and $\mathrm{Fe}^{2+}$, but this ordering is driven by the site preferences of the non-divalent cations.

The $B$-group cations occupy the $M(4)$ cavity (Fig. 3) and link the octahedron strip to the tetrahedron doublechain in the $b$ direction. The constituent cations $\mathrm{Ca}$, $\mathrm{Mn}^{2+}, \mathrm{Fe}^{2+}, \mathrm{Mg}, \mathrm{Na}$ and $\mathrm{Li}$ show a wide range of size (from 0.72 to $1.02 \AA$ for [6]-coordination); the exact position of the cation within the cavity depends on its size: the large cations $(\mathrm{Ca}, \mathrm{Na})$ are further away from the margin of the octahedron strip than are the small cations $\left(\mathrm{Mn}^{2+}, \mathrm{Fe}^{2+}, \mathrm{Mg}, \mathrm{Li}\right)$. Indeed, multiple occupancy of

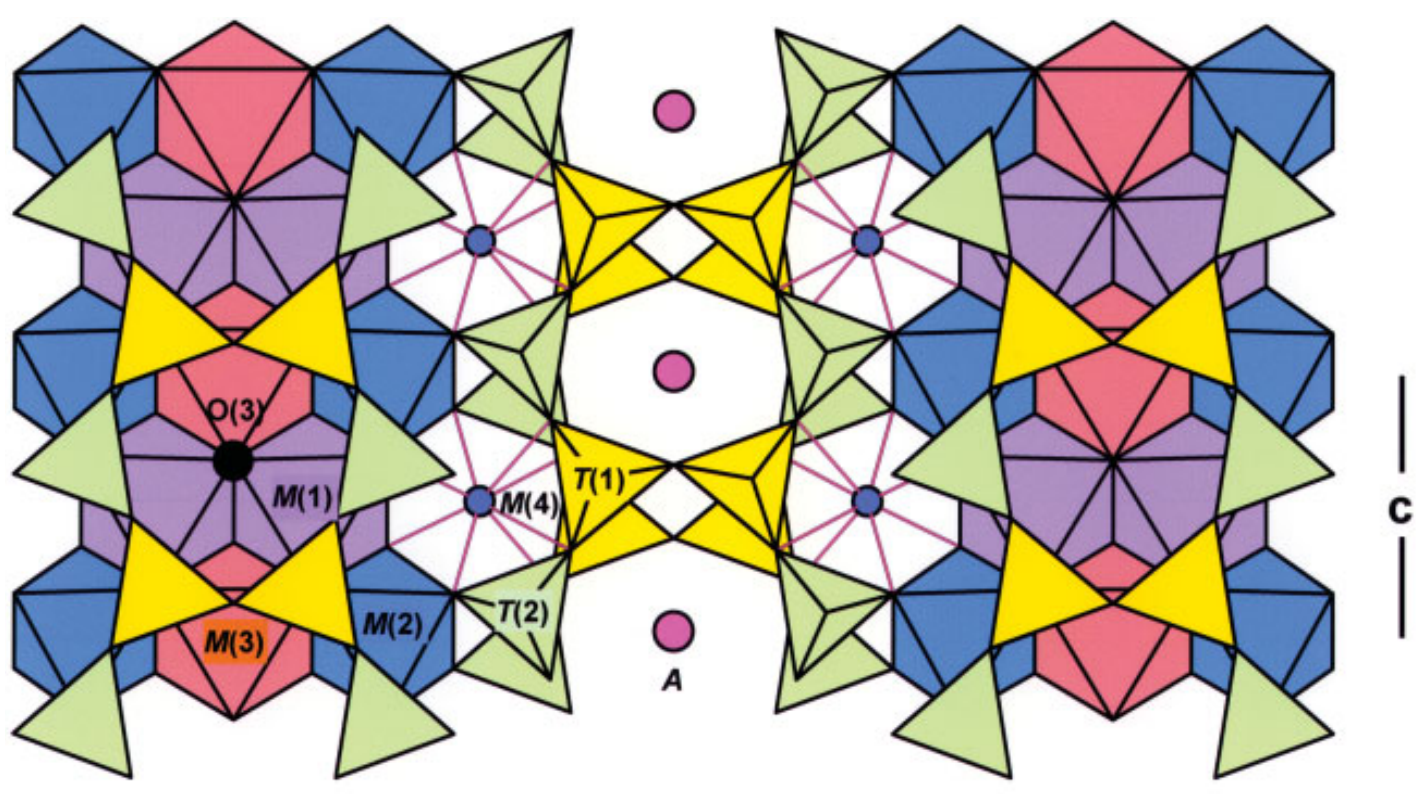

b

FIG. 3. The $C 2 / m$ amphibole structure projected onto (100). 
the cavity can lead to the identification of two distinct sites in a single crystal, the $M(4)$ site and $M(4)$ ' site. However, it seems unlikely that a single cation species will disorder over the $M(4)$ and $M(4)^{\prime}$ sites.

The A-group cations occupy the $A$ cavity (Fig. 3 ). There are several distinct sites within this cavity (Fig. 4), and it is not clear if all of them actually can be occupied, as attaining an adequate model for the electron density in this cavity during crystal-structure refinement is nontrivial. However, it seems likely that only the $A(m)$ and $A(2)$ sites are occupied. K occupies $A(m)$ (Papike et al. 1969 , Hawthorne 1983), and $\mathrm{Na}$ occupies both $A(m)$ and $A(2)$, the relative occupancies of these sites being dependent on SRO arrangements at the nearest-neighbor cation sites (Hawthorne et al. 1996a).

The $W$-group anions occupy the $\mathrm{O}(3)$ site. The sizes of these anions show a considerable range and yet there seems to be continuous solid-solution between $(\mathrm{OH})$ and $\mathrm{F},(\mathrm{OH})$ and $\mathrm{O}^{2-}$, and $(\mathrm{OH})$ and $\mathrm{Cl}$ for several amphiboles.

\section{(OH) AS A Probe of LOCAL ORdeR IN AMPHIBOLE}

The $\mathrm{O}(3)$ site and its local environment are illustrated in Figure 5. Where $\mathrm{O}(3)=(\mathrm{OH})$, the $\mathrm{O}-\mathrm{H}$ distance is $\sim 0.96 \AA$ (Hawthorne \& Grundy 1976) and the associated $\mathrm{O}-\mathrm{H}$ bond is approximately orthogonal to (100) (Hanisch 1966). The $\mathrm{O}(3)$ anion bonds to two $M(1)$ and one $M(3)$ cations. The point symmetry of the $\mathrm{O}(3)$ site is $m$ in the $C 2 / m$ amphibole structure, but inspection of Figure 5 shows that there is pseudo-trigonal symmetry along the $\mathrm{O}-\mathrm{H}$ bond, a very important factor that affects the resolution of the infrared spectra (Strens 1966).

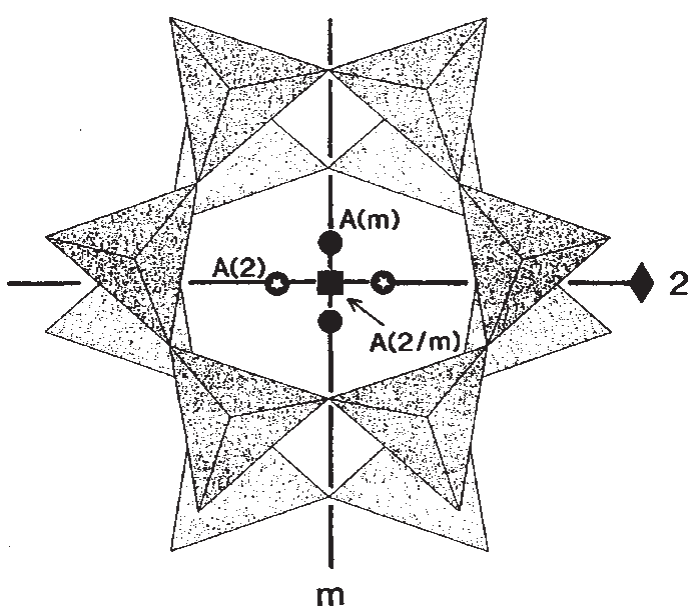

FIG. 4. Possible $A$ sites in the $A$ cavity of the $C 2 / m$ amphibole structure.
SRO and the assignment of bands in the infrared spectrum

Consider two cation species (e.g., $\mathrm{Mg}$ and $\mathrm{Fe}^{2+}$ or $\mathrm{Mg}$ and $\mathrm{Co}^{2+}$ ) at the (two) $M(1)$ and (one) $M(3)$ sites. As $\mathrm{O}(3)$ bonds to these $M$ sites, there are $2 \times 2 \times 2=8$ different possible short-range arrangements around an $(\mathrm{OH})$ anion at $\mathrm{O}(3)$; these are listed in Table 1 . The spectrum that results from this situation (Fig. 6) shows only four absorption bands. The difference in the number of observed bands and the number of possible short-range arrangements arises from the pseudotrigonal nature of the local arrangement: the two $M(1)$ and one $M(3)$ cations are pseudosymmetrically related, introducing an accidental degeneracy into the spectrum (Table 1). The bands in the spectrum of Figure 6 are labeled A, B, C and $\mathrm{D}$, and their assignments are shown in Table 1.

\section{Band intensities in the spectra}

As the bands A, B, C and D are related to different short-range arrangements of the $M(1)$ and $M(3)$ cations around $\mathrm{O}(3)$, the relative intensities of these bands are related to the relative frequencies of occurrence of these short-range arrangements in the structure; moreover, the sum of all the short-range arrangements must be equal to the bulk composition. Strens $(1966,1974)$ derived the criteria to identify both LRO and SRO, but Law (1976) showed that these criteria are not correct. Law (1976) developed a model for LRO assuming no SRO is present, but application to two amphiboles characterized by crystal-structure refinement and Mössbauer spectroscopy showed poor agreement between the various site-occupancies.

Following Strens (1966, 1974) and Law (1976), we write the site occupancies and $C$-group-cation composition as follows:

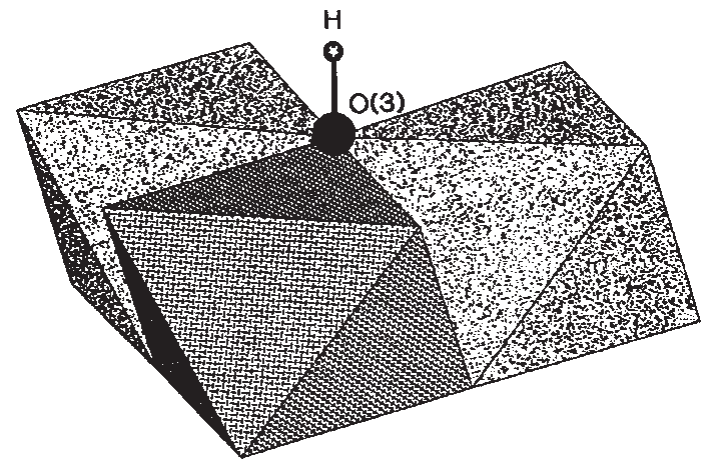

FIG. 5. The $(\mathrm{OH})$ group in the amphibole structure, associated with the $M(1)$ (random dots) and $M(3)$ (crosses) polyhedra. The $\mathrm{O}$ atom at the $\mathrm{O}(3)$ site is shown as a black circle, and its associated $\mathrm{H}$ atom is shown as a starred circle. 


$$
\begin{aligned}
& \mathrm{y}_{M(1)}=M^{2+} \text { at } M(1) \\
& \mathrm{y}_{M(3)}=M^{2+} \text { at } M(3) \\
& \mathrm{x}_{M(1)}=\mathrm{Mg} \text { at } M(1) \\
& \mathrm{x}_{M(3)}=\mathrm{Mg} \text { at } M(3) \\
& \mathrm{X}=\text { total } \mathrm{Mg} \text { at } M(1,3)=2 \mathrm{x}_{M(1)}+\mathrm{x}_{M(3)} \\
& \mathrm{Y}=\text { total } M^{2+} \text { at } M(1,3)=2 \mathrm{y}_{M(1)}+\mathrm{y}_{M(3)}
\end{aligned}
$$

We may express all occupancies in terms of $\mathrm{x}$ and $\mathrm{y}$ by manipulating equations (1) and (2):

$$
\begin{aligned}
& \mathrm{x}_{M(1)}=1-\mathrm{y}_{M(1)}=1-1 / 2\left[\mathrm{Y}-\mathrm{y}_{M(3)}\right] \\
& \mathrm{y}_{M(1)}=1 / 2\left[\mathrm{Y}-\mathrm{y}_{M(3)}\right] \\
& \mathrm{x}_{M(3)}=1-\mathrm{y}_{M(3)}
\end{aligned}
$$

For no SRO, the relative intensities of the bands,

\begin{tabular}{|c|c|c|c|c|c|}
\hline & $M(1)$ & $M(1)$ & $M(3)$ & Band $^{*}$ & Band \\
\hline (1) & $\mathrm{Mg}$ & $\mathrm{Mg}$ & $\mathrm{Mg}$ & A & A \\
\hline (2) & $\mathrm{Mg}$ & $\mathrm{Mg}$ & $M^{2+}$ & $\mathrm{B}^{\prime}$ & \\
\hline (3) & $M^{2+}$ & $\mathrm{Mg}$ & $\mathrm{Mg}$ & $R^{\prime \prime}$ & B \\
\hline (4) & $\mathrm{Mg}$ & $M^{2+}$ & $\mathrm{Mg}$ & & \\
\hline (5) & $\overrightarrow{M^{2+}}$ & $M^{R^{+}}$ & $\mathrm{Mg}$ & $\mathrm{C}^{\prime}$ & \\
\hline (6) & $M^{2+}$ & $\mathrm{Mg}$ & $\mathrm{M}^{++}$ & $C^{\prime \prime}$ & c \\
\hline (7) & $\mathrm{Mg}$ & $\mathrm{M}^{+}$ & $M^{2^{+}}$ & $C^{\prime \prime}$ & \\
\hline (8) & $M^{2^{+}}$ & $M^{A^{+}}$ & $M^{R^{+}}$ & D & D \\
\hline
\end{tabular}
$\mathrm{I}^{\mathrm{C}}{ }_{\mathrm{A}, \mathrm{B}, \mathrm{C}, \mathrm{D}}$ are given by

$$
\begin{aligned}
& \mathrm{I}_{\mathrm{A}}^{\mathrm{C}}=\mathrm{x}_{M(1)}{ }^{2} \mathrm{x}_{M(3)} \\
& \mathrm{I}_{\mathrm{B}}{ }_{\mathrm{B}}=\mathrm{x}_{M(1)}{ }^{2} \mathrm{y}_{M(3)}+2 \mathrm{x}_{M(1)} \mathrm{y}_{M(1)} \mathrm{x}_{M(3)} \\
& \mathrm{I}_{\mathrm{C}}{ }_{\mathrm{C}}=\mathrm{y}_{M(1)} \mathrm{x}_{M(3)}+2 \mathrm{x}_{M(1)} \mathrm{y}_{M(1)} \mathrm{y}_{M(3)} \\
& \mathrm{I}_{\mathrm{D}}{ }_{\mathrm{D}}=\mathrm{y}_{M(1)}{ }^{2} \mathrm{y}_{M(3)}
\end{aligned}
$$

where the superscript $\mathrm{C}$ on the band intensities denotes that they are calculated values. Substituting (3) into (4) gives the following:

TABLE 1. POSSIBLE LOCAL ARRANGEMENTS AROUND THE O(3) SITE IN AMPHIBOLES WITH $\left(\mathrm{Mg}, M^{*}\right)$ AT M(1) AND M(3)

* ideal band-structure; (3) and (4) are symmetry-equivalent and give rise to only one band: $\mathrm{B}^{\prime \prime}$; similarly, (5) and (6) are symmetry-equivalent and give rise to only one band: $\mathrm{C}^{\prime \prime}$.

+ band structure usually observed; (2) and [(3) + (4)] are pseudosymmetrically degenerate, and only one band $(B)$ is observed experimentally; similarly, (5) and [(6) * (7)] are pseudosymmetrically degenerate, and only one band (C) is observed experimentally.

$$
\begin{aligned}
& \mathrm{I}_{\mathrm{A}}^{\mathrm{C}}=\left(1-1 / 2\left[\mathrm{Y}-\mathrm{y}_{M(3)}\right]^{2}\right)\left(1-\mathrm{y}_{M(3)}\right) \\
& \mathrm{I}_{\mathrm{B}} \mathrm{C}_{\mathrm{B}}=\left(1-1 / 2\left[\mathrm{Y}-\mathrm{y}_{M(3)}\right]\right)^{2} \mathrm{y}_{M(3)}+ \\
& 2\left(1-1 / 2\left[\mathrm{Y}-\mathrm{y}_{M(3)}\right]\right)^{1 / 2}\left[\mathrm{Y}-\mathrm{y}_{M(3)}\right]\left(1-\mathrm{y}_{M(3)}\right) \\
& \mathrm{I}_{\mathrm{C}} \mathrm{C}_{1 / 4}\left[\mathrm{Y}-\mathrm{y}_{M(3)}\right]^{2}\left(1-\mathrm{y}_{M(3)}\right)+ \\
& 2\left(1-1 / 2\left[\mathrm{Y}-\mathrm{y}_{M(3)}\right]\right) 1 / 2\left[\mathrm{Y}-\mathrm{y}_{M(3)}\right] \mathrm{y}_{M(3)} \\
& \mathrm{I}_{\mathrm{D}}{ }_{\mathrm{D}}=1 / 2\left[\mathrm{Y}-\mathrm{y}_{M(3)}\right]^{2} \mathrm{y}_{M(3)}
\end{aligned}
$$

Equation (5) gives the calculated intensities of the bands as a function of cation order (i.e., $\left.\mathrm{y}_{M(3)}\right)$ for a specific composition Y where there is no SRO present (i.e., there is short-range disorder). Following Law (1976), we may assume that there is no SRO and use equation (5) to derive the state of LRO from the observed values

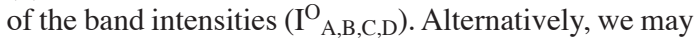
measure the state of LRO (i.e., $\mathrm{y}_{M(3)}$ ) by some other method (e.g., Rietveld refinement, Raudsepp et al. 1987, Della Ventura et al. 1993a, b) and use the observed $\left(\mathrm{I}_{\mathrm{A}, \mathrm{B}, \mathrm{C}, \mathrm{D})}\right)$ and calculated $\left(\mathrm{I}_{\mathrm{A}, \mathrm{B}, \mathrm{C}, \mathrm{D})}^{\mathrm{C}}\right)$ band intensities to derive information on SRO of divalent cations over

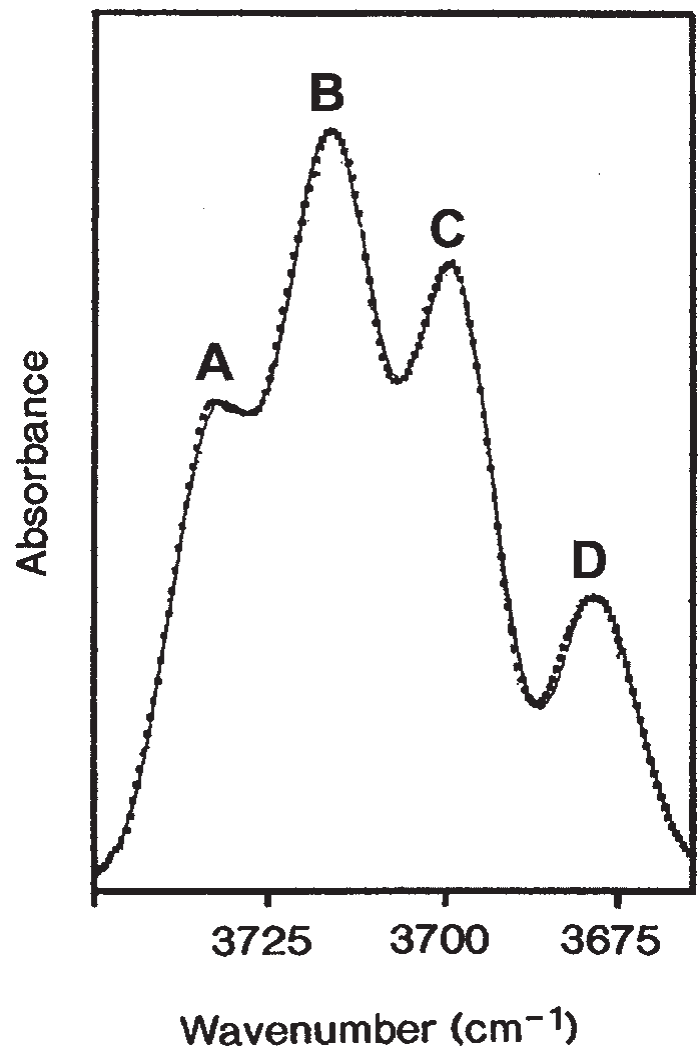

FIG. 6. The infrared spectrum in the principal $\mathrm{OH}$-stretching region of a synthetic $(\mathrm{Mg}, \mathrm{Co})$-bearing potassium-richterite of composition $\mathrm{K}(\mathrm{CaNa})\left(\mathrm{Mg}_{3} \mathrm{Co}_{2}\right) \mathrm{Si}_{8} \mathrm{O}_{22}(\mathrm{OH})_{2}$. From Hawthorne et al. (1996d). 
the $M(1)$ and $M(3)$ sites (Hawthorne et al. 1996d, Della Ventura et al. 1996a).

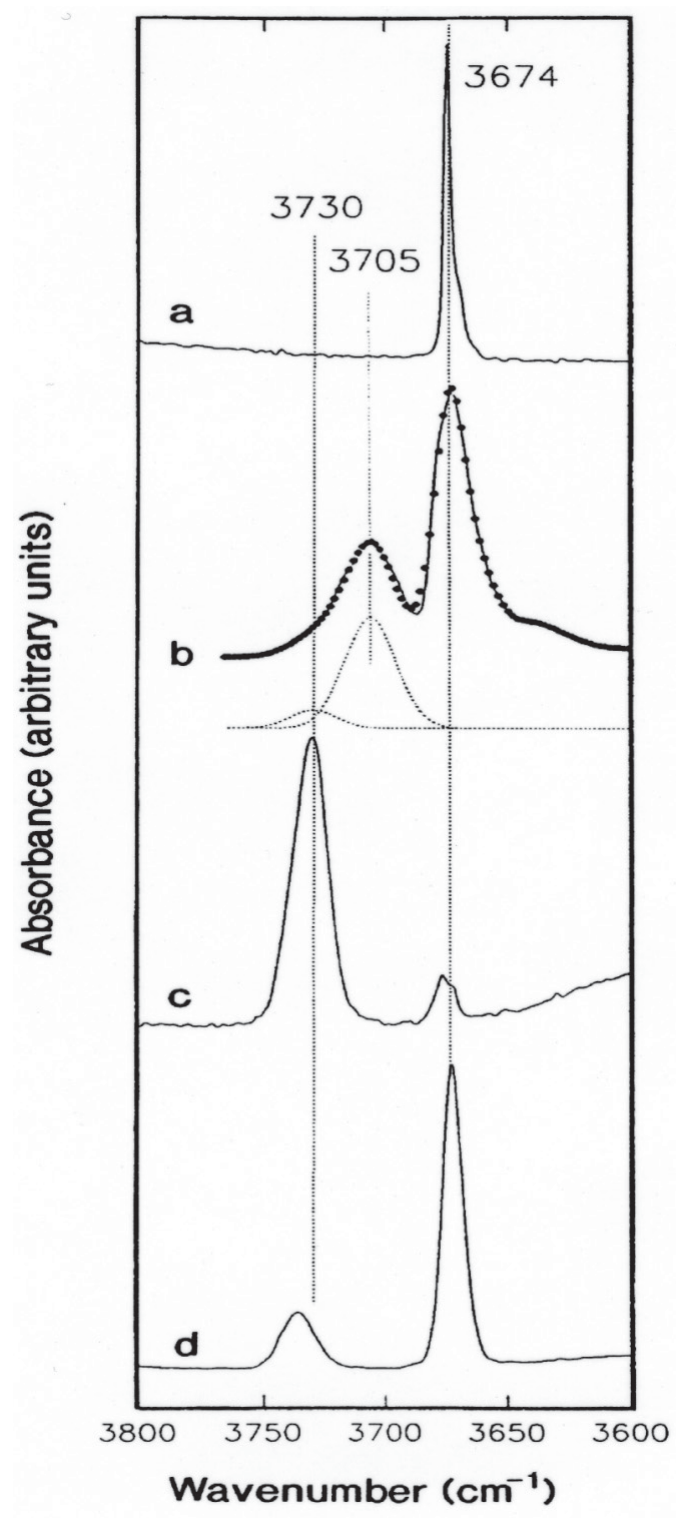

FIG. 7. Infrared absorption spectra in the principal $(\mathrm{OH})$ stretching region for (a) synthetic tremolite, (b) tremolite (56) of Hawthorne \& Grundy (1976), (c) synthetic richteritewith a minor tremolite component, (d) synthetic tremolite-potassium-richterite of composition $\mathrm{TR}_{80} \mathrm{KR}_{20}$. The dotted peaks in (b) represent two component bands of the higher-energy peak. From Hawthorne et al. (1996c).

\section{SRO of Heterovalent Cations in Tremolite}

Hawthorne et al. (1996c) first showed that strong SRO of cations does occur in monoclinic amphiboles. Figure 7 a shows the infrared spectrum of synthetic tremolite of composition close to $\square\left(\mathrm{Ca}_{1.8} \mathrm{Mg}_{0.2}\right) \mathrm{Mg}_{5}$ $\mathrm{Si}_{8} \mathrm{O}_{22}(\mathrm{OH})_{2}$, and Figure $7 \mathrm{~b}$ shows the spectrum of tremolite (56) (Hawthorne 1983), the composition of which is given in Table 2. The spectrum of synthetic tremolite consists of an intense narrow band at 3674 $\mathrm{cm}^{-1}$ due to the configuration $\mathrm{MgMgMg}-(\mathrm{OH})[\mathrm{M}(1)=$ $\mathrm{M}(3)=\mathrm{Mg}]$, together with a narrow shoulder at $\sim 3670$ $\mathrm{cm}^{-1}$ due to the configuration $\mathrm{MgMgMg}-(\mathrm{OH})$ with a neighboring $M(4)$ site(s) occupied by $\mathrm{Mg}$ rather than by $\mathrm{Ca}$. The spectrum of tremolite in Figure $7 \mathrm{~b}$ also has an intense band at $3674 \mathrm{~cm}^{-1}$, in accord with the makeup of its $C$-group cations. However, there is also an intense band at $3705 \mathrm{~cm}^{-1}$ in the spectrum of Figure $7 \mathrm{~b}$, and the composition of this amphibole indicates that this band must be related to occupancy of the $A, M(4)$ and $T(1)$ sites by cations not present in synthetic tremolite [i.e., ${ }^{A}(\mathrm{Na}, \mathrm{K}),{ }^{M(4)} \mathrm{Na}$ and $\left.{ }^{T(1)} \mathrm{Al}\right]$. Hence the bands in the principal $(\mathrm{OH})$-stretching region of the infrared must also be affected by not just the cations that are nearest neighbors to the $\mathrm{O}(3)$ anion, but also by cations that are next-nearest-neighbors of $\mathrm{O}(3)$.

\section{Infrared absorption of related amphiboles}

Table 2 shows that the tremolite under consideration has significant $(\mathrm{Na}, \mathrm{K})$ at the $A$ site, $\mathrm{Na}$ at the $M(4)$ site and $\mathrm{Al}$ at the $T(1)$ site. Let us first consider the effect of $(\mathrm{Na}, \mathrm{K})$ at the $A$ site on the $\mathrm{MgMgMg}-(\mathrm{OH})$ absorption. This may be assessed by examining the infrared spectra of synthetic richterite (Fig. 7c) of nominal end-member composition, $\mathrm{Na} \mathrm{Ca} \mathrm{Na} \mathrm{Mg}_{5}$ $\mathrm{Si}_{8} \mathrm{O}_{22}(\mathrm{OH})_{2}$, and synthetic tremolite - potassiumrich richterite solid-solution of nominal composition $\mathrm{TR}_{80} \mathrm{KR}_{20}$ (Fig. 7d). In synthetic richterite, the principal absorption occurs at $3730 \mathrm{~cm}^{-1}$ with a minor peak at

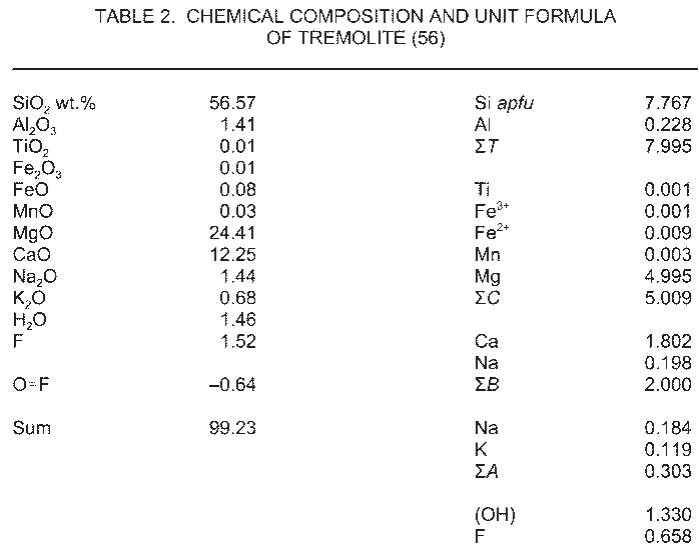


$3674 \mathrm{~cm}^{-1}$ (Fig. 7c), whereas in synthetic TR ${ }_{80} \mathrm{KR}_{20}$, the principal absorption occurs at $3674 \mathrm{~cm}^{-1}$ with a minor peak at $3738 \mathrm{~cm}^{-1}$ (Fig. 7d). The bands at 3730 and $3738 \mathrm{~cm}^{-1}$ are assigned to the local arrangement $\mathrm{MgMgMg}-(\mathrm{OH})$ with a neighboring $A$ site occupied by $\mathrm{Na}$ and $\mathrm{K}$, respectively, which we will refer to as the richterite (or potassium-rich richterite) arrangement. In the spectrum of synthetic $\mathrm{TR}_{80} \mathrm{KR}_{20}$ (Fig. $7 \mathrm{~d}$ ), the band at $3674 \mathrm{~cm}^{-1}$ can be assigned to the local arrangement $\mathrm{MgMgMg}-(\mathrm{OH})$ with a neighboring $A$-site vacant, which we will refer to as the tremolite arrangement. A band due to the tremolite arrangement also occurs in the spectrum of synthetic richterite (Fig. 7c), indicating that it is not of end-member composition, but has significant vacancy at the $A$ site.

\section{The effect of next-nearest-neighbor cations}

Let us now consider the possible local arrangements of next-nearest-neighbor cations (Table 3) in tremolite of composition given in Table 2. Obviously, arrangements of the type $\mathrm{MgMgMg}-\mathrm{F}$ do not give rise to an $(\mathrm{OH})$-stretching absorption. However, the $\mathrm{O}(3)$ sites occur in pairs along the edge of the $M(1)$ octahedron, and the occurrence of $(\mathrm{OH})-\mathrm{F}$ arrangements here may or may not give rise to additional bands. Arrangement (1) (Table 3) is the tremolite configuration and gives a band at $3674 \mathrm{~cm}^{-1}$. Substitution of $\mathrm{F}$ in tremolite (Robert et al. 1999) does not give rise to any additional bands (one-mode behavior) and hence arrangement (2) will not give rise to an $(\mathrm{OH})$ absorption. Arrangement (3) is the richterite (potassium-rich richterite) configuration and gives a band at $3730(3738) \mathrm{cm}^{-1}$. Arrangement (4) involves $\mathrm{F}$ at the neighboring $\mathrm{O}(3)$ site. As shown by Della Ventura et al. (1998b) and Robert et al. (1999), this arrangement gives rise to an additional band at 3714 $\mathrm{cm}^{-1}$ in both F-bearing richterite and potassium-rich richterite (two-mode behavior). Substitution of $\mathrm{Al}$ for $\mathrm{Si}$ in micas reduces the frequency of the principal absorption band by $\sim 25 \mathrm{~cm}^{-1}$ (e.g., Redhammer et al. 2000). Because the local arrangement around $(\mathrm{OH})$ in richterite and potassium-rich richterite is similar to that in Si-rich micas, substitution of $\mathrm{Al}$ for $\mathrm{Si}$ in a local richterite-type configuration will reduce the frequency of the principal

TABLE 3. POSSIBLELOCAL ARRANGEMENTS AND PREDICTED BAND-FREQUENCIES FOR TREMOLITE (56)

\begin{tabular}{cccccc}
\hline & $A$ & $\mathrm{O}(3)$ & $T(1)$ & $M(4)$ & Frequency \\
\hline$(1)$ & $\square$ & $\mathrm{OH}$ & $\mathrm{Si}$ & $\mathrm{Ca}$ & 3674 \\
$(2)$ & $\square$ & $\mathrm{F}$ & $\mathrm{Si}$ & $\mathrm{Ca}$ & 3674 \\
$(3)$ & $(\mathrm{Na}, \mathrm{K})$ & $\mathrm{OH}$ & $\mathrm{Si}$ & $\mathrm{Na}$ & 3730 \\
$(4)$ & $(\mathrm{Na}, \mathrm{K})$ & $\mathrm{F}$ & $\mathrm{Si}$ & $\mathrm{Na}$ & 3714 \\
$(5)$ & $\square$ & $(\mathrm{OH}, \mathrm{F})$ & $\mathrm{Al}$ & $\mathrm{Ca}$ & 3649 \\
$(6)$ & $(\mathrm{Na}, \mathrm{K})$ & $\mathrm{OH}$ & $\mathrm{Al}$ & $\mathrm{Ca}$ & 3705 \\
$(7)$ & $(\mathrm{Na}, \mathrm{K})$ & $\mathrm{F}$ & $\mathrm{Al}$ & $\mathrm{Ca}$ & 3689 \\
& & & & & \\
\hline
\end{tabular}

The frequency is expressed in $\mathrm{cm}^{1}$.
(OH)-absorption band by $\sim 25 \mathrm{~cm}^{-1}$. Similarly, substitution of $\mathrm{Al}$ for $\mathrm{Si}$ in a local tremolite configuration [arrangement (5)] would reduce the frequency of the principal $(\mathrm{OH})$ absorption to give a band at $3674-25=$ $3649 \mathrm{~cm}^{-1}$. Substitution of Al for Si in a local richteritetype configuration [arrangement (6)] would reduce the frequency of the principal $(\mathrm{OH})$ absorption to give a band at $3730-25=3705 \mathrm{~cm}^{-1}$. Substitution of $\mathrm{Al}$ for $\mathrm{Si}$ in a local richterite-type configuration with $\mathrm{F}$ at an adjacent $\mathrm{O}(3)$ site [arrangement (7)] would reduce the frequency of the principal $(\mathrm{OH})$ absorption to give a band at $3714-25=3689 \mathrm{~cm}^{-1}$.

\section{Derivation of patterns of SRO}

We may now compare the band positions and local arrangements of Table 3 with the observed bands in Figure 7b. Arrangement (1), with its band at 3674 $\mathrm{cm}^{-1}$, is obviously the dominant local arrangement in this amphibole. The weak intensity of the band at $3730 \mathrm{~cm}^{-1}$ in Figure $7 \mathrm{~b}$ is not in accord with all the $A$ cations being involved in arrangement (3). Arrangement (4) would give rise to a band at $3714 \mathrm{~cm}^{-1}$ that is significantly displaced from the maximum at $3705 \mathrm{~cm}^{-1}$; this arrangement may be present in a minor amount, but the spectrum is not compatible with most of the $\mathrm{F}$ being involved in this arrangement. Arrangement (5) is obviously not present, as there is no trace of a band at $3649 \mathrm{~cm}^{-1}$ in the spectrum. Arrangement (6) will give rise to a band at $3705 \mathrm{~cm}^{-1}$. As the dominant secondary band in the spectrum is at $3705 \mathrm{~cm}^{-1}$ (Fig. 7b), we may conclude that this arrangement is the second most frequent arrangement in this crystal. There is no band at $3689 \mathrm{~cm}^{-1}$ corresponding to arrangement (7), and hence this arrangement does not occur.

Thus the two most important local arrangements in our tremolite (56) are (1) and (6) (Table 3). However, arrangement (3) involves equal amounts of ${ }^{A}(\mathrm{Na}, \mathrm{K})$ and ${ }^{T(1)} \mathrm{Al}$, and inspection of the formula of the tremolite (Table 2) shows that ${ }^{A}(\mathrm{Na}, \mathrm{K})$ exceeds ${ }^{T(1)} \mathrm{Al}$. The excess ${ }^{A}(\mathrm{Na}, \mathrm{K})$ gives rise to a small amount of arrangement (3) and is in accord with the weak band at $3730 \mathrm{~cm}^{-1}$ in the spectrum (Fig. 7b). As none of the arrangements identified so far as being present involve $\mathrm{F}$, there must be a fourth arrangement that does involve this component. Inspection of Table 3 shows that arrangement (2) is the only possibility. Note that we cannot use the relative intensities of the bands to derive accurate estimates of the amounts of these arrangements present in the amphibole: first, the absorptivity is related to relative concentration in a complex way that is currently not understood (Skogby \& Rossman 1991, Hawthorne et al. 1997); second, arrangements that involve $F$ have no spectral expression. However, despite this limitation, it is apparent that the non-tremolite components in the amphibole of Table 2 are not randomly distributed within the amphibole structure but show extreme SRO. 


\section{Bond-VALENCE AsPeCtS OF SRO}

Brown (1981, 2002) has developed a simple but powerful approach to chemical bonding in inorganic structures. A crystal is considered as an array of atoms connected by a network of chemical bonds. Any path through this network consists of alternating cations and anions, and the total array is subject to the constraint of electroneutrality. Bond valence is a measure of the strength of a chemical bond, and can be calculated from the curves of Brown \& Altermatt (1985) if the bond lengths are known. The valence-sum rule states that the sum of the bond valences incident at each atom is equal to the magnitude of the formal valence of that atom. If the interatomic distances are not known, the bond valences can be approximated by the formal Pauling bond-strengths (Pauling 1929). Bond-valence arguments are normally applied to the long-range aspects of a structure, and Preiser et al. (1999) have shown how bond-valence theory can be derived from an ionic model. However, Burdett \& Hawthorne (1993) showed how aspects of the theory can be derived from a localized molecular-orbital description of a solid in which there is a significant energy-gap between interacting orbitals on adjacent atoms. This finding suggests that bond-valence theory can also be applied to local arrangements within a structure, and Hawthorne (1997) applied such arguments to derive the most probable arrangements of SRO in a wide variety of monoclinic amphiboles. A key feature of this approach is the application of the valence-sum rule to all possible short-range arrangements: those arrangements that most closely conform to the valence-sum rule are the shortrange arrangements that are most likely to occur.

Of course, except in completely ordered amphiboles (in which the patterns of LRO are also the patterns of SRO), we do not know the local bond-lengths. There are two ways in which we can approach this problem: (1) we can use the formal Pauling bond-strengths; (2) we can take the observed bond-valences in an amphibole in which the LRO is similar to that in the structure of interest (usually the structure of the amphibole of interest itself) and modify them by the ratio of the formal aggregate charge of the ions at a site to the formal charge of the ions at that site in the SRO arrangement under consideration.

SRO of heterovalent cations in tremolite (56): application of bond-valence theory

Let us apply these ideas of bond-valence theory to the example of tremolite (56) considered in the previous section. As indicated in Table 2, the principal non-tremolite components in this amphibole are ${ }^{A}(\mathrm{Na}$, $\mathrm{K}),{ }^{M(4)} \mathrm{Na}$ and ${ }^{T(1)} \mathrm{Al}$. The environment of these sites is shown in Figure 8. Of key importance here are the $\mathrm{O}(5), \mathrm{O}(6)$ and $\mathrm{O}(7)$ anions that link to the $A(2), M(4)$ and $T(1)$ sites, as the bond valences incident at these sites will be strongly affected by the local occupancies of the $A(2), M(4)$ and $T(1)$ sites. Table 4 shows the bond valences of the cation arrangements of Table 3 (exclusive of those involving $\mathrm{F}$ ).

Arrangement (1) is the ordered tremolite configuration and has incident bond-valence sums in accord with the valence-sum rule. Arrangement (3) is the richterite configuration; it also has reasonable bond-valence sums, and corresponds with both the chemical composition of the crystal and the weak band at $3730 \mathrm{~cm}^{-1}$ in the spectrum of Figure 7b. Arrangement (5) has $\mathrm{Al}$ at $T(1)$, $\mathrm{Ca}$ at $M(4)$ and a vacant $A$-site; the bond-valence sums are very low, indicating that this local arrangement will not occur, in agreement with the absence of a band at $3649 \mathrm{~cm}^{-1}$. For arrangement (6), the bond-valence sum for $\mathrm{O}(5)$ is low, and the sums for $\mathrm{O}(6)$ and $\mathrm{O}(7)$ are acceptable. As arrangements (5) and (6) are the only arrangements that include $\mathrm{Al}$ at $T(1)$, it is a question of which arrangement is to be preferred. From the sums in Table 4, it is clear that (6) is the preferred arrangement, in accord with the band position at $3705 \mathrm{~cm}^{-1}$ (Table 3). Other arrangements are also (combinatorially) possible, specifically those that just involve the addition or replacement of one component, but these are unfavorable from a bond-valence perspective.

\section{Nearest- and NeXt-Nearest-Neighbor EfFects}

The simple example given above shows that nextnearest-neighbor (NNN) effects give rise to significant bands in the spectra of amphiboles, which is very fortunate as these NNN "effects" are our short-range arrangements of atoms, and the presence and intensities of the resultant bands contain information on SRO. Before we consider any specific amphiboles, we need to charac-

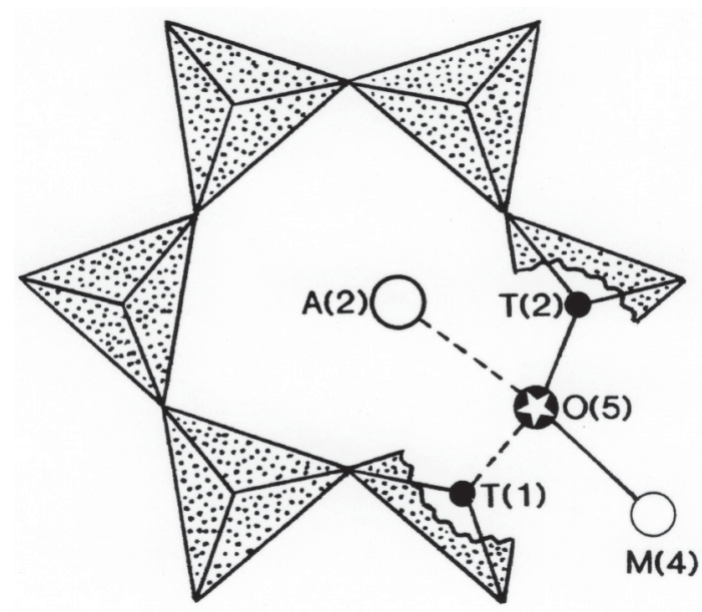

FIG. 8. The $A(2), M(4)$ and $T(1)$ sites in tremolite, together with their coordinating anions and neighboring coordination-polyhedra. 
terize the local arrangements of sites that are involved in these possible patterns of SRO, and we also need to develop a nomenclature to denote these site configurations (note that we use the term "configuration" when we are dealing with sites, and the term "arrangement" when we are dealing with atoms).

\section{Nearest-neighbor sites}

The $\mathrm{O}(3)$ site is bonded to two $M(1)$ and one $M(3)$ sites (Fig. 5), and the $\mathrm{H}$ atom of that $\mathrm{O}(3)$ site interacts with the cation at the $A$ site. Hence we may denote this configuration of sites as $M(1) M(1) M(3)-\mathrm{O}(3)-A$, and local arrangements of atoms will be written as follows: $\mathrm{MgMgMg}-\mathrm{OH}-\square$... end-member tremolite, $\mathrm{MgMgMg}-\mathrm{OH}-\mathrm{Na} . .$. end-member richterite.
Next-nearest-neighbor sites: the T sites

Consider the local environment of the $\mathrm{H}$ atom in the monoclinic amphibole structure (Fig. 9). The $\mathrm{H}$ atom is in such a position as to form a hydrogen bond to the closest $\mathrm{O}(7)$ atom (Hawthorne 1983), and it is the strength of this interaction that affects the shift in the frequency of the principal $\mathrm{OH}$-stretching vibration. So what affects the strength of this hydrogen bond? The key issue here is that the valence-sum rule must be satisfied at the $\mathrm{O}(7)$ anion, and this is affected only by the atoms occupying the locally associated pair of $T$ (1) sites (Fig. 9). We can incorporate the T(1)T(1) configuration by appending it to the site-configuration symbol: $M(1) M(1) M(3)-\mathrm{O}(3)-A: T(1) T(1)$.

TABLE 4. LOCAL BOND-VALENCE $(v u)$ PATTERNS FOR SELECTED LOCAL ARRANGEMENTS OF TABLE 3

\begin{tabular}{|c|c|c|c|c|c|c|c|c|c|c|c|}
\hline \multicolumn{6}{|c|}{ ARRANGEMENT (1) } & \multicolumn{6}{|c|}{ ARRANGEMENT (3) } \\
\hline & ${ }^{M(44)} \mathrm{Ca}$ & ${ }^{A} \square$ & ${ }^{\pi(1)} \mathrm{Si}$ & ${ }^{r(2)} \mathrm{Si}$ & $\Sigma$ & & ${ }^{M(44)} \mathrm{Na}$ & ${ }^{A} \mathrm{Na}$ & $r_{(1)} \mathrm{Si}$ & ${ }^{T(2)} \mathrm{Si}$ & $\Sigma$ \\
\hline $\mathrm{D}(5)$ & 0.13 & - & 0.97 & 0.92 & 2 & $O(5)$ & 0.06 & 0.07 & 0.99 & 0.91 & 2 \\
\hline $\mathrm{O}(6)$ & 0.21 & - & 0.98 & 0.88 & 2.1 & $O(6)$ & 0.1 & 0.08 & 0.95 & 0.86 & 2 \\
\hline$O(7)$ & - & - & $1.02^{\times 2}$ & - & 2 & $\mathrm{O}(7)$ & - & 0.18 & $0.96^{\times 2}$ & - & 2.1 \\
\hline \multicolumn{6}{|c|}{ ARRANGEMENT (5) } & \multicolumn{6}{|c|}{ ARRANGEMENT (6) } \\
\hline & ${ }^{M(4)} \mathrm{Ca}$ & ${ }^{A} \square$ & ${ }^{\pi(1)} \mathrm{Al}$ & ${ }^{T(2)} \mathrm{Si}$ & $\Sigma$ & & ${ }^{M(4)} \mathrm{Ca}$ & ${ }^{A} \mathrm{Na}$ & ${ }^{T(1)} \mathrm{Al}$ & ${ }^{T(2)} \mathrm{Si}$ & $\Sigma$ \\
\hline$O(5)$ & 0.13 & - & 0.73 & 0.91 & 1.8 & $\mathrm{O}(5)$ & 0.13 & 0.07 & 0.73 & 0.91 & 1.8 \\
\hline$O(6)$ & 0.21 & - & 0.74 & 0.86 & 1.8 & $O(6)$ & 0.21 & 0.08 & 0.74 & 0.86 & 1.9 \\
\hline$O(7)$ & - & - & $\begin{array}{l}0.76+ \\
1.02\end{array}$ & - & 1.8 & $O(7)$ & - & 0.18 & $\begin{array}{l}0.76+ \\
1.02\end{array}$ & - & 2 \\
\hline
\end{tabular}

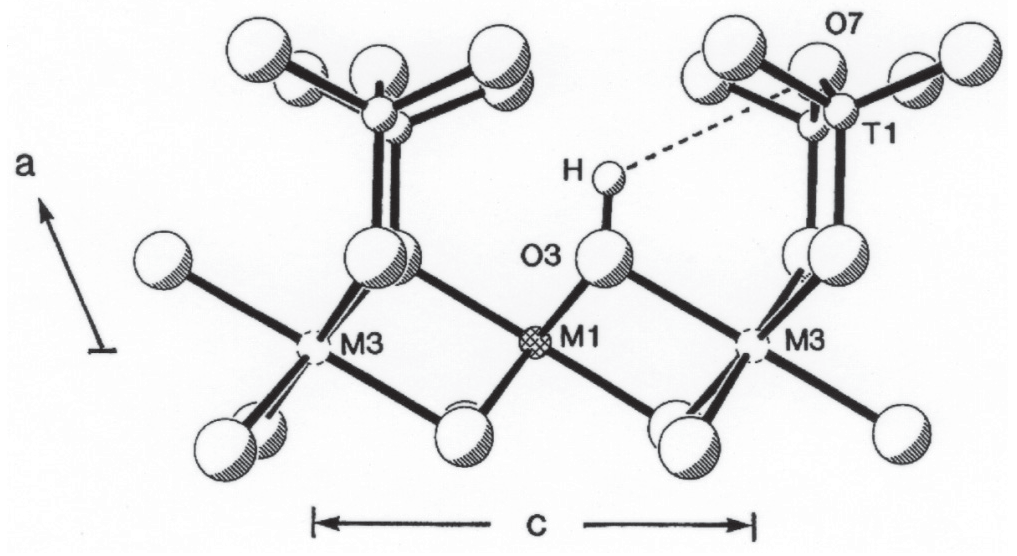

FIG. 9. The local environment of the $\mathrm{H}$ atom in the monoclinic amphibole structure viewed down [010] with perspective; the $T(2)$ sites have been omitted for clarity. From Della Ventura et al. (1999). 


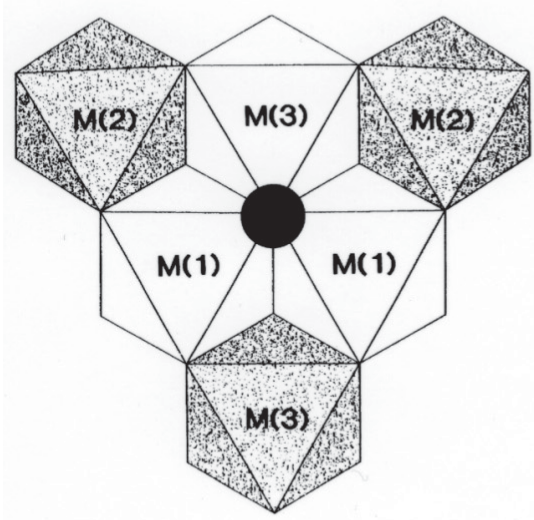

(a)

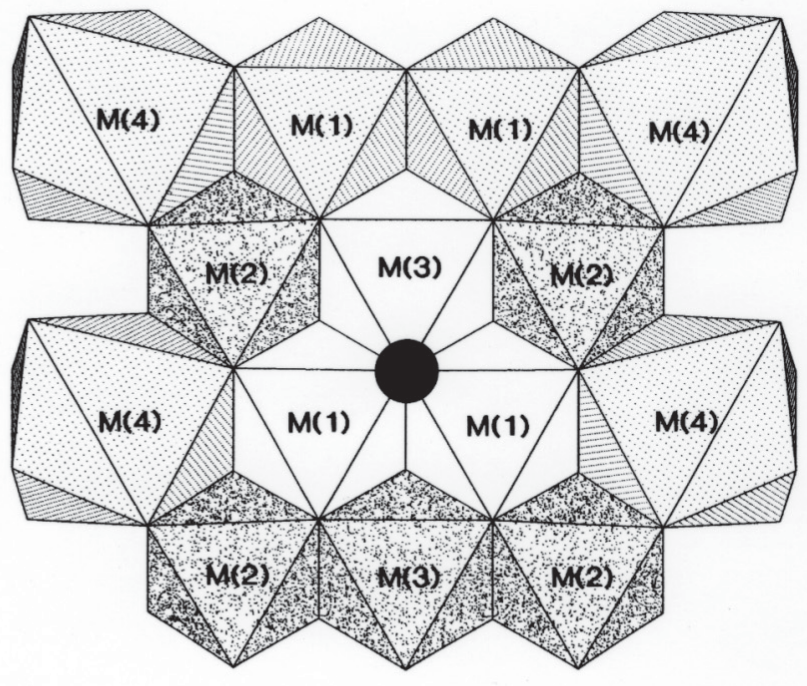

(b)

FIG. 10. Nearest-neighbor (unstippled) and next-nearest-neighbor (stippled) octahedra about the $\mathrm{O}(3)$ site in the monoclinic amphibole structure; the $\mathrm{O}(3)$ site is marked by a large black circle. Modified from Della Ventura et al. (1999).

\section{Next-nearest-neighbor sites: the $M$ sites}

The NN and NNN $M$ sites are shown in Figure 10. We know that the next-next-nearest-neighbor sites will not give rise to additional bands, as these sites include the $M(4)$ sites, and occupancy of that site by both $\mathrm{Na}$ and $\mathrm{Ca}$ in richterite does not produce fine structure, although it does produce band broadening (band splitting of a few wavenumbers that is not resolved in the spectrum). Hence only the $M(2)$ and $M(3)$ sites may produce discrete bands in the infrared. The issue now is which $M(2)$ and $M(3)$ sites are involved in this effect. Della Ventura et al. (1999) discussed this issue and noted that there are (at least) two models (Fig. 10). In the first (simpler) model (Fig. 10a), we consider the three NNN $M$ sites $M(2) M(2) M(3)$, whereas in the second model (Fig. 10b), we consider the five NNN $M$ sites $M(2) M(2) M(3) M(2) M(2)$; note that the second model also could consider the two $M(1)$ sites as well, but these are occupied solely by $\mathrm{Mg}$ in the composition currently considered (see below) and hence will not contribute to this effect. We incorporate this $M(2) M(2) M(3)$ configuration into our site configuration symbol as follows: $M(1) M(1) M(3)-\mathrm{O}(3)-A$ : $T(1) T(1)-M(2) M(2) M(3)$ or $M(1) M(1) M(3)-\mathrm{O}(3)-A$ : $T(1) T(1)-M(2) M(2) M(3) M(2) M(2)$.
The number of possible

short-range arrangements of cations

Let us examine our site-configuration symbol $M(1) M(1) M(3)-\mathrm{O}(3)-A: T(1) T(1)-M(2) M(2) M(3)$ to see how many local configurations are possible. This problem depends on the number of species that are available for incorporation; we will consider this problem for a relatively straightforward example. Let the $M(1)$ and $M(3)$ sites be occupied by $\mathrm{Mg}$ and $\mathrm{Al}$, the $\mathrm{O}(3)$ site be occupied only by $(\mathrm{OH})$, the $A$ site be occupied by $\mathrm{Na}, \square$ and $\mathrm{Ca}$, and the $T(1)$ site be occupied by $\mathrm{Si}$ and Al. Setting pseudosymmetric arrangements as identical, the NN $M(1)$ and $M(3)$ sites give rise to four arrangements: $\mathrm{MgMgMg}, \mathrm{MgMgAl}, \mathrm{MgAlAl}$ and AlAlAl; the $A$ site gives rise to three arrangements: Na, $\square$ and $\mathrm{Ca}$; the NNN T(1) site pair gives rise to three arrangements: $\mathrm{SiSi}, \mathrm{SiAl}$ and $\mathrm{AlAl}$; the $\mathrm{NNN} M(2)$ and $M(3)$ sites give rise to four arrangements: $\mathrm{MgMgMg}$, $\mathrm{MgMgAl}, \mathrm{MgAlAl}$ and AlAlAl. Thus the total number of algebraically possible arrangements is $4 \times 3 \times 3 \times 4$ $=144$; if we extend the NNN arrangement of octahedra to the next two $M(2)$ sites, this number rises to $144 \times 3$ $=432$. Of course, many of these arrangements will be unstable on bond-valence grounds (Hawthorne 1997), but a random short-range arrangement of cations would give rise to this many arrangements for this particular composition. 


\section{Resolution of infrared spectra}

This problem was examined by Della Ventura et al. (1999) who synthesized amphiboles along the richterite-pargasite join. The spectrum of richterite is well understood, and thus this gives us a start in spectrum fitting and assignment. The general approach here is to fit one model to all the spectra of the series, as in this way we can considerably increase the number of observations without greatly increasing the number of fitting parameters. We can identify the key features of this approach as follows: (1) numerical fitting of the spectra to component bands must be congruent for all spectra; (2) the intensities of the component bands must vary systematically with changes in chemical composition, and (3) the variations in order derived from the spectral assignments must be in accord with the variation in cell dimensions across the series.

\section{SRO IN RICHTERITE-PARGASITE SOLID-SOLUTIONS}

The infrared spectrum of pargasite has long been known to be a complicated spectrum. Semet (1973) noted the presence of two broad bands centered on 3711 and $3678 \mathrm{~cm}^{-1}$, and suggested that these are due to Al$\mathrm{Mg}$ disorder over the $M(1)$ and $M(3)$ sites. Raudsepp et al. $(1987,1991)$ presented similar spectra for pargasite and $M^{3+}$-substituted pargasite $\left(M^{3+}=\mathrm{Cr}, \mathrm{Sc}, \mathrm{In}\right)$, and found that the lower-frequency band is shifted to lower wavenumber in substituted pargasite, in accord with the replacement of $\mathrm{Al}$ by a heavier trivalent cation at the $M(1,3)$ sites. Welch et al. (1994) showed an analogous ${ }^{1} \mathrm{H}$ MAS NMR spectrum for pargasite. However, the very broad bands in the infrared spectra indicate that there are more than two components in the spectra, but

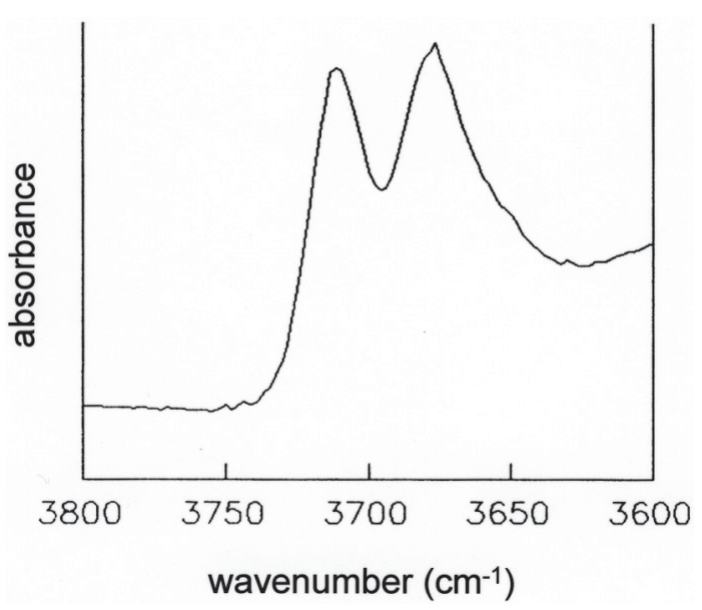

FIG. 11. The infrared spectrum of pargasite in the principal OH-stretching region. From Della Ventura et al. (1999). inspection of the spectrum of pargasite (Fig. 11) shows that there is not a lot of information in the envelope on additional components; indeed, the pargasite spectrum does not contain sufficient information to allow a completely independent and unique fit of component bands (Hawthorne \& Waychunas 1988).

Early crystal-structure studies on pargasite assumed that ${ }^{[6]} \mathrm{Al}$ is completely ordered at the $M(2)$ site. However, Semet (1973) and Raudsepp et al. (1987, 1991) showed that this is not the case. Detailed crystalstructure work by Oberti et al. (1995b) showed that ${ }^{[6]} \mathrm{Al}$ is partly disordered over the $M(2)$ and $M(3)$ sites in Mg-rich pargasite, the degree of disorder increasing with increase in the amount of $\mathrm{Mg}$ in the structure. Della Ventura et al. (1998a) showed that ${ }^{[6]} \mathrm{Al}$ is disordered in synthetic pargasite but completely ordered at $M(2)$ in the Co analogue $\mathrm{Na} \mathrm{Ca}_{2}\left(\mathrm{Co}^{2+}{ }_{4} \mathrm{Al}\right)\left(\mathrm{Si}_{6} \mathrm{Al}_{2}\right) \mathrm{O}_{22}(\mathrm{OH})_{2}$.

Fitting of spectra for the richterite-pargasite solid-solution

The fitted spectra of this series are shown in Figure 12. The fitting process started with the top spectrum of Figure 12, and then proceeded through to the bottom spectrum of Figure 12, fixing the positions of the peaks present in the previous spectra (these constraints were relaxed somewhat once all the spectra were fitted). More extensive details are given in Della Ventura et al. (1999).

\section{The number of stable arrangements}

Above, we showed that there are 144 algebraically distinct arrangements for the configuration symbol $M(1) M(1) M(3)-\mathrm{O}(3)-A: T(1) T(1)-M(2) M(2) M(3)$, and 432 distinct arrangements for the configuration symbol $M(1) M(1) M(3)-\mathrm{O}(3)-A: T(1) T(1)-M(2) M(2) M(3)$ $M(2) M(2)$. Let us consider the case for the simpler configuration. Using the bond-valence arguments of Hawthorne (1997), we can reduce this number somewhat to what is possible with regard to the local valencematching principle. Any arrangement with two or three $\mathrm{Al}$ at $M(1) M(1) M(3)$ will lead to an unacceptable excess in bond valence at $\mathrm{O}(3)$ (1.33 and $1.50 v u$ using Pauling bond-strengths), and hence only $\mathrm{MgMgMg}$ and $\mathrm{MgMgAl}$ can occur, reducing the number to $144 / 2=$ 72. Although $\mathrm{Ca}$ can occur at the $A$ site in monoclinic amphiboles (Hawthorne et al. 1996e), it is unlikely that such an arrangement is possible in the absence of $\mathrm{F}$, as Ca would get too close to the $\mathrm{H}$ atom of the $(\mathrm{OH})$ group at $\mathrm{O}(3)$. Examination of pargasitic amphiboles (plus fluorocannilloite, Hawthorne et al. 1996e) shows that $\mathrm{F}$ is always in excess of ${ }^{A} \mathrm{Ca} \times 2$ (Fig. 13). Thus only $\mathrm{Na}$ and $\square$ are possible at the $A$ site, reducing the number of arrangements to $72 \times 2 / 3=48$. The local arrangement $T(1) T(1)=\mathrm{AlAl}$ cannot occur as it requires local association of $\mathrm{Ca}$ at the $A$ site (which we show above does not occur in the absence of F) to avoid 


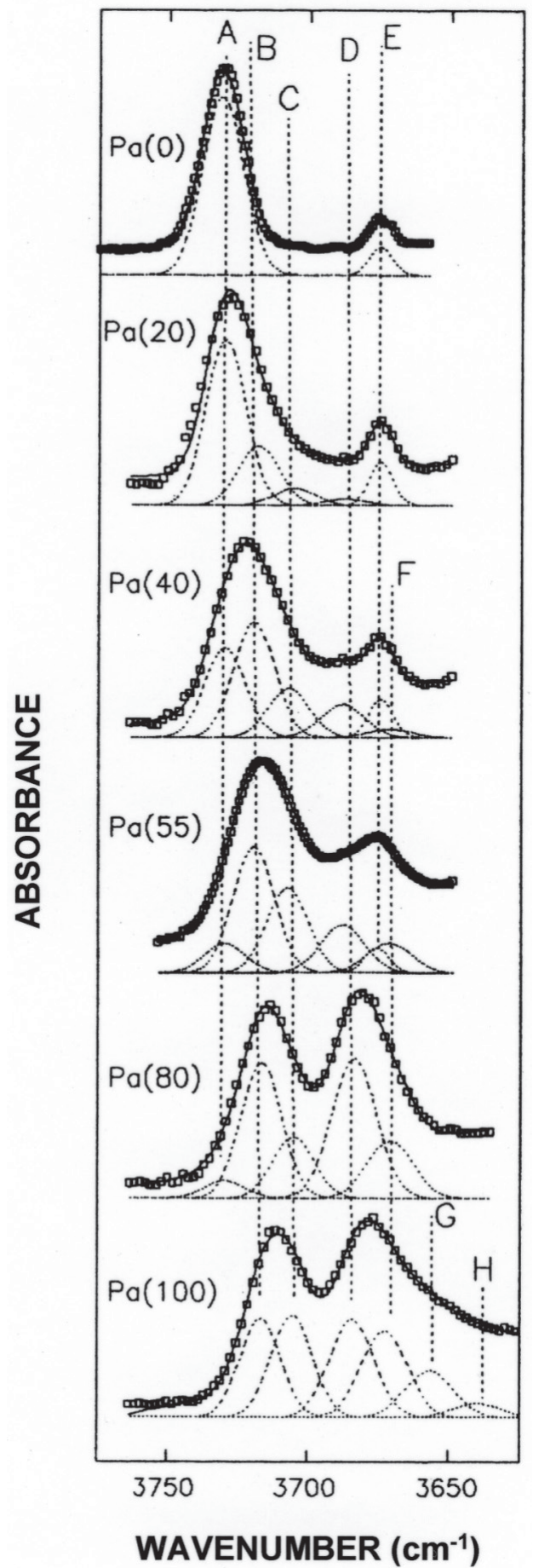

FIG. 12. Resolution of the infrared spectra of richterite-pargasite solid-solutions into component bands A to H. From Della Ventura et al. (1999). unacceptably low bond-valence sums at the $\mathrm{O}(7)$ site, and hence the number further decreases to $48 \times 2 / 3$ $=32$. The four possible arrangements of NNN cations [at the $M(2) M(2) M(3)$ sites] are $\mathrm{MgMgMg}, \mathrm{MgMgAl}$, $\mathrm{MgAlAl}$ and $\mathrm{AlAlAl}$; neither AlAlAl nor MgAlAl can occur with the $\mathrm{NN}$ arrangement $\mathrm{MgMgAl}$ as an excess of bond valence results at the anions linked to two $\mathrm{Al}$ cations, reducing the number to $32 / 2=16$.

\section{Band assignment}

Note that in end-member pargasite with complete LRO of Al and $\mathrm{Si}$ at the $T$ sites, the arrangement $T(1) T(1)=$ SiSi cannot occur, as the bulk composition of the crystal would also force an equal number of arrangements of the type $T(1) T(1)=\mathrm{AlAl}$, and these cannot occur because of the absence of $\mathrm{F}$ (and hence ${ }^{\mathrm{A}} \mathrm{Ca}$ ), resulting in low bond-valence sums incident at the $\mathrm{O}(7)$ anion. This argument is in accord with the spectra of Figure 12. Band A, which we assign to the $\mathrm{MgMgMg}-$ $(\mathrm{OH})-\mathrm{Na}: \mathrm{SiSi}-\mathrm{MgMgMg}$ arrangement in richterite, decreases in intensity with increasing pargasite content in the amphibole, to disappear at end-member pargasite (and hence the number of possible local arrangements in end-member pargasite reduces to $16 / 2=8$ ). Bands $\mathrm{B}$ and $\mathrm{C}$ involve $\mathrm{NN}$ arrangements of the form $\mathrm{MgMgMg}-\mathrm{OH}-\mathrm{Na}$; they also have to incorporate ${ }^{[4]} \mathrm{Al}$ and hence have the NNN arrangement $T(1) T(1)=\mathrm{SiAl}$. Bands $\mathrm{D}$ and $\mathrm{F}$ involve $\mathrm{NN}$ arrangements of the form $\mathrm{MgMgAl}-\mathrm{OH}-\mathrm{Na}$; they also have to incorporate ${ }^{[4]} \mathrm{Al}$ and hence have the NNN arrangement $T(1) T(1)=\mathrm{SiAl}$. So what distinguishes between bands $\mathrm{B}$ and $\mathrm{C}$ ? This is the NNN arrangement involving the $M(2)$ and $M(3)$ sites: $\mathrm{MgMgMg}$ and $\mathrm{AlMgMg}$, respectively. The origin of the $\mathrm{D}$ and $\mathrm{F}$ bands is somewhat more obscure. The $\mathrm{G}$

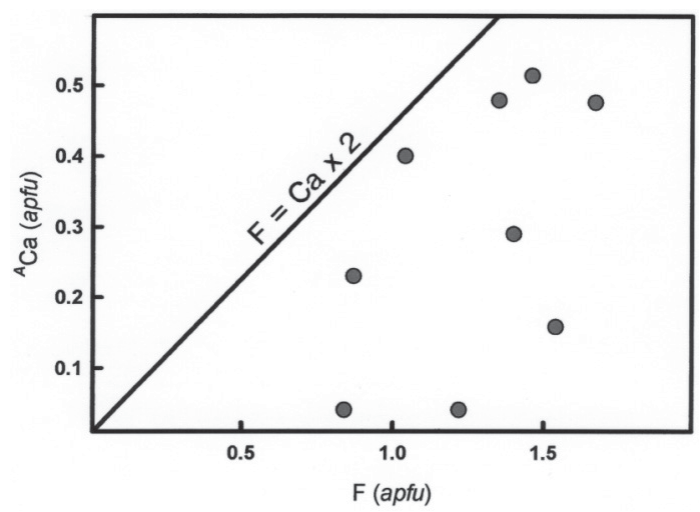

FIG. 13. The variation in $\mathrm{Ca}$ at the $A$ site, ${ }^{A} \mathrm{Ca}$, as a function of $\mathrm{F}$ content in Ca-rich amphiboles; the diagonal line shows the relation $2 \times{ }^{A} \mathrm{Ca}=\mathrm{F}$, and to the right of the line, there is always more than sufficient $\mathrm{F}$ to be associated with $\mathrm{Ca}$ in the $A$ cavity. 
and $\mathrm{H}$ bands occur only in end-member pargasite, and were assigned to NNN $M$-site configurations involving one and two $\mathrm{Al}$ atoms, respectively (Della Ventura et al. 1999): $\mathrm{MgMgAl}-(\mathrm{OH})-\mathrm{Na}: \mathrm{SiAl}-\mathrm{MgMgMgAlMg}$ and $\mathrm{MgMgAl}-(\mathrm{OH})-\mathrm{Na}: \mathrm{SiAl}-\mathrm{MgMgMgAlAl}$. However, if this is the case, this raises the issue of why bands of the form $\mathrm{MgMgMg}-(\mathrm{OH})-\mathrm{Na}: \mathrm{SiAl}-\mathrm{MgMgMgAlMg}$ and $\mathrm{MgMgMg}-(\mathrm{OH})-\mathrm{Na}: \mathrm{SiAl}-\mathrm{MgMgMgAlAl}$ are not present. The alternative is that bands $\mathrm{G}$ and $\mathrm{H}$ could be due to arrangements $\mathrm{MgMgMg}-(\mathrm{OH})-\mathrm{Na}$ : SiAl-MgAlAl and MgMgAl-(OH)-Na: SiAl-MgAlAl. However, it was difficult at the moment to argue convincingly for one assignment versus the other.

The above interpretation is developed for complete LRO of $\mathrm{Al}$ and $\mathrm{Si}$ at the $T$ sites. Oberti et al. (1995a) have shown that some $\mathrm{Al}$ does occur at the $T(2)$ site in pargasitic amphiboles crystallized at high temperature, and Welch et al. (1998) have shown this to be the case in high-temperature synthetic pargasite using ${ }^{29} \mathrm{Si}$ MAS NMR. If this is the case for the pargasite examined in Figure 12, the number of possible SRO arrangements in pargasite increases significantly.

Short-range order is extensive in amphiboles of the richterite-pargasite series. The short-range arrangements that occur are those that most closely obey the valence-matching principle applied to local arrangements. Studies of amphiboles of the tremolite-magnesiohornblende series (Hawthorne et al. 2000a) and the tremolite-pargasite series (Della Ventura et al. 2003) show similar results.

\section{SHORT-RANGe ORDER-DisORDER OF $(\mathrm{OH})$ AND F IN AMPHIBOLES}

Many monoclinic amphiboles show solid solution in terms of $(\mathrm{OH})$ and $\mathrm{F}$, but little has been published on the mechanism of this solid solution: do $(\mathrm{OH})$ and $\mathrm{F}$ show complete short-range disorder, or is this substitution associated with SRO? Infrared spectroscopy can provide us with a window into this type of behavior. Della Ventura et al. (1998b) and Robert et al. (1999) examined (OH)-F solid-solutions in tremolite-fluorotremolite, richterite-fluororichterite and potassium fluororichterite of intermediate composition. The salient feature of all these amphiboles is that the $M(1), M(2)$ and $M(3)$ sites are occupied only by $\mathrm{Mg}$; hence the only NN $M(1) M(1) M(3)$ arrangement that occurs is $\mathrm{MgMgMg}$, and the NNN $M$-site arrangements involve only $\mathrm{Mg}$. Similarly, the $T(1)$ sites are occupied only by $\mathrm{Si}$. Hence all local arrangements are as follows: $\mathrm{MgMgMg}-(\mathrm{OH})-\square: \mathrm{SiSi}-\mathrm{MgMgMg}$ and $\mathrm{MgMgMg}-(\mathrm{OH})-\mathrm{Na}: \mathrm{SiSi}-\mathrm{MgMgMg}$, and their F-analogues $\mathrm{MgMgMg}-\mathrm{F}-\square: \mathrm{SiSi}-\mathrm{MgMgMg}$ and $\mathrm{MgMgMg}-\mathrm{F}-\mathrm{Na}: \mathrm{SiSi}-\mathrm{MgMgMg}$ that are invisible in the infrared. The only potential for local order involves $(\mathrm{OH})$ and $\mathrm{F}$ at $\mathrm{O}(3)$ sites adjacent to the $(\mathrm{OH})$ group of the arrangement.

\section{One-mode and two-mode behavior}

In amphiboles of the tremolite-fluorotremolite series, there is a single $(\mathrm{OH})$-stretching band at 3674 $\mathrm{cm}^{-1}$ (Jenkins et al. 1997, Gottschalk et al. 1999, Robert et al. 1999). The position of this band does not change significantly with decreasing $\mathrm{F}$ content of the amphibole, but the band intensity decreases monotonically with decreasing F content (Fig. 14a). The occurrence of only one band in such circumstances is called onemode behavior. In the amphiboles of the richterite-fluororichterite series, the spectra are more complicated (Fig. 14b). The richterite spectrum contains a single intense band $\mathrm{A}$ at $3730 \mathrm{~cm}^{-1}$ due to the arrangement $\mathrm{MgMgMg}-(\mathrm{OH})-\mathrm{Na}: \mathrm{SiSi}-\mathrm{MgMgMg}$, together with a weak band $\mathrm{C}$ at $3674 \mathrm{~cm}^{-1}$ due to the arrangement $\mathrm{MgMgMg}-(\mathrm{OH})-\square: \mathrm{SiSi}-\mathrm{MgMgMg}$ from the minor tremolite component in the amphibole. The spectrum of fluororichterite with a nominal F content of $1.2 \mathrm{apfu}$ contains a single intense band $\mathrm{A}$ at $3730 \mathrm{~cm}^{-1}$ due to the arrangement $\mathrm{MgMgMg}-(\mathrm{OH})-\mathrm{Na}: \mathrm{SiSi}-\mathrm{MgMgMg}$, together with a weak band $\mathrm{C}$ at $3674 \mathrm{~cm}^{-1}$ due to the arrangement $\mathrm{MgMgMg}-(\mathrm{OH})-\square: \mathrm{SiSi}-\mathrm{MgMgMg}$ from the minor tremolite component, plus an additional band $\mathrm{B}$ of intermediate intensity at $3711 \mathrm{~cm}^{-1}$. The appearance of a new band in such circumstances is known as two-mode behavior (Chang \& Mitra 1968). Moreover, with increasing $\mathrm{F}$ content of the amphibole, the intensity of the $\mathrm{B}$ band increases at the expense of the A band.

The stereochemistry of local coupling within the amphibole structure

The one-mode behavior of tremolite-fluorotremolite solid-solution indicates that local arrangements involving an $(\mathrm{OH})$ group are not significantly affected by adjacent arrangements involving $\mathrm{F}$. Thus we may conclude that in tremolite-fluorotremolite, there is no coupling between adjacent $\mathrm{O}(3)$ anions, either through the $\mathrm{O}(3)-\mathrm{O}(3)$ edge in the octahedron strip or across the vacant $A$-site cavity. The two-mode behavior of richterite-fluororichterite solid-solutions indicates that the local arrangement involving an $(\mathrm{OH})$ group is significantly affected by adjacent arrangements involving $\mathrm{F}$. The only local difference between tremolite and richterite is that the $A$-site cavity is vacant in tremolite and is occupied by $\mathrm{Na}$ in richterite, indicating that the two-mode behavior in the latter is due to coupling of arrangements across the $A$-site cavity through the resident $\mathrm{Na}$ atom.

What factors are pertinent to the possibility of coupling across the $A$ cavity? First, comparison of the principal $(\mathrm{OH})$-stretching frequency in tremolite (3674 $\left.\mathrm{cm}^{-1}\right)$ and richterite $\left(3730 \mathrm{~cm}^{-1}\right)$ indicates that there is a strong repulsive interaction between $\mathrm{H}$ and $\mathrm{Na}$ at the $A$ site. Second, comparison of the electron-density arrangements in the $A$ cavity where $\mathrm{O}(3)=\mathrm{F}$ and where $\mathrm{O}(3)=(\mathrm{OH})($ Fig. 15) indicates that Na occupies a more 

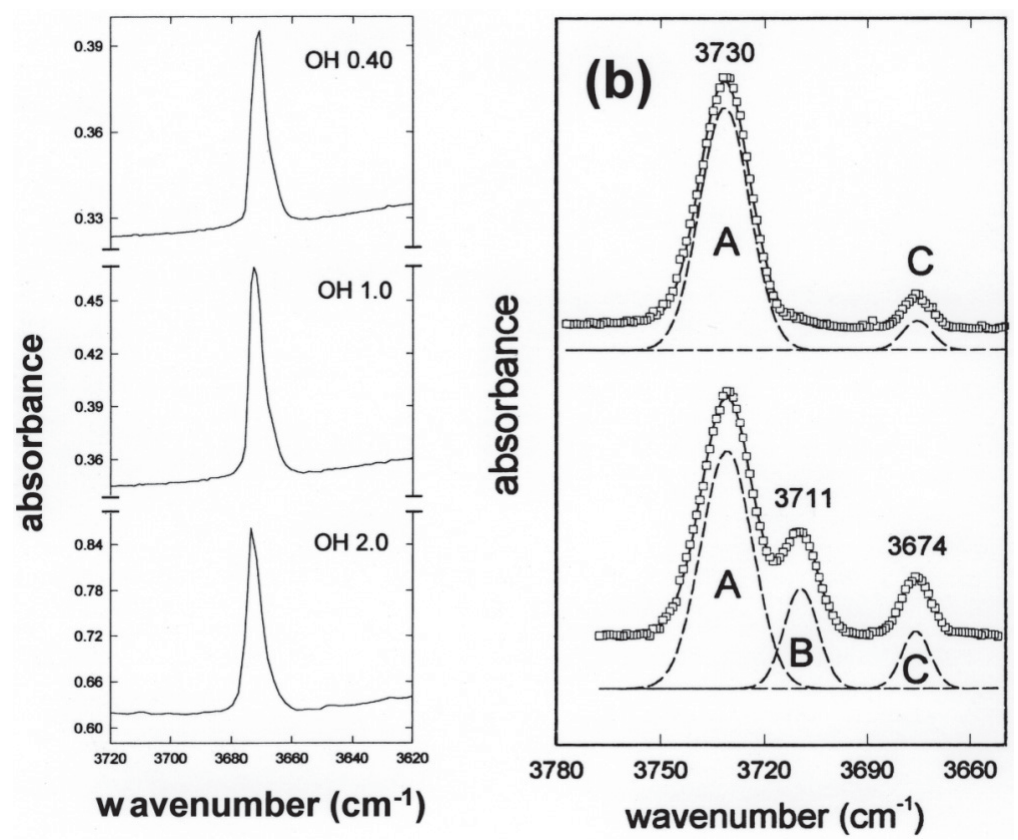

FIG. 14. Infrared spectra in the principal $(\mathrm{OH})$-stretching region for (a) amphiboles of the tremolite-fluorotremolite solid-solution, and (b) amphiboles of the richterite-fluororichterite solid-solution. From Robert et al. (1999).

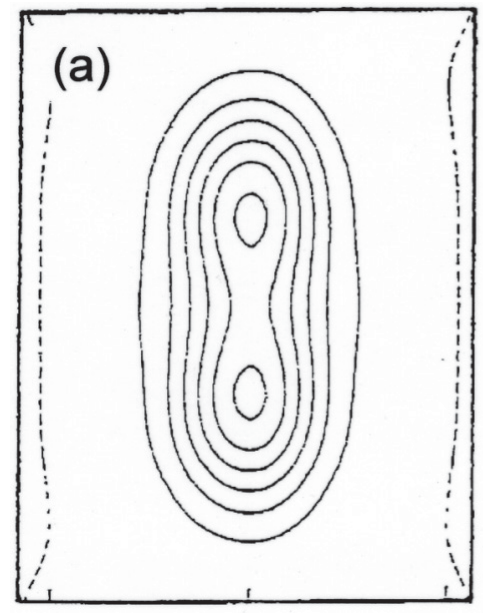

(b)

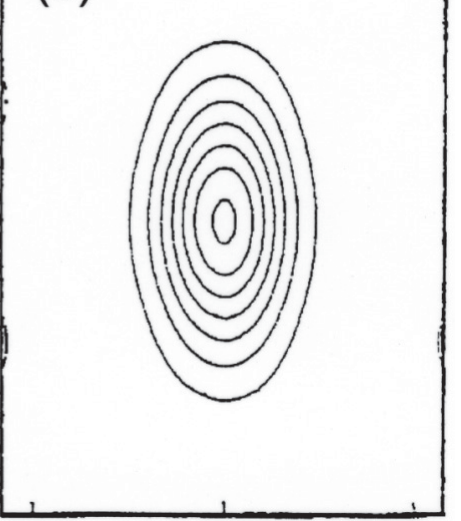

FIG. 15. Electron-density distribution in the $A$ cavity projected on to ( $\overline{2} 01)$ in (a) fluoroarfvedsonite, and (b) arfvedsonite; contour interval is $1 e / \AA^{3}$, width of map $=2.2 \AA$. From Hawthorne et al. (1996a). 
central position in the cavity if $\mathrm{O}(3)=(\mathrm{OH})$ than if $\mathrm{O}(3)$ $=\mathrm{F}$. As a result, an $(\mathrm{OH})$ group will interact less strongly with $\mathrm{Na}$ when the opposing $\mathrm{O}(3)$ site is occupied by $\mathrm{F}$ rather than by $(\mathrm{OH})$. Hence Na will move toward $\mathrm{F}$ and away from $(\mathrm{OH})$, reducing the repulsive interaction between $\mathrm{H}$ and $\mathrm{Na}$ and causing the constituent $(\mathrm{OH})$ group to absorb at a lower frequency (as is observed for band B in the spectrum of fluororichterite (Fig. 14b).

\section{Local arrangements in $(\mathrm{OH}, \mathrm{F})$-bearing amphibole solid-solutions}

In order to interpret quantitatively the spectra presented here, we have to understand what is happening around the $A$ site in these amphiboles. This issue is examined in Figure 16, which shows sketches of all possible arrangements around the $A$ cavity in richterite and tremolite. In richterite, where both $\mathrm{O}(3)$ sites are occupied either by $(\mathrm{OH})$ [arrangement (1)] or by $\mathrm{F}$ [arrangement (3)], Na interacts equally with each $(\mathrm{OH})$ group, whereas if one $\mathrm{O}(3)$ site is occupied by $(\mathrm{OH})$ and the other is occupied by $\mathrm{F}, \mathrm{Na}$ moves toward $\mathrm{F}$ [and away from $(\mathrm{OH})$ ], giving rise to the second band [arrangement (2)]. In tremolite, the occupancy of one $\mathrm{O}(3)$ site does not affect the other $\mathrm{O}(3)$ site, as there is no $A$ cation to transmit this effect across the cavity.

\section{Testing for SRO of $(\mathrm{OH})$ and $\mathrm{F}$ in richterite}

Let us now consider the quantitative effect of the arrangements in Figure 16 on the infrared spectra. There are three important points here: (1) arrangements (3) and (6) are invisible to infrared in the principal $(\mathrm{OH})$ stretching region; (2) arrangements (4) and (5) will give rise to degenerate principal $(\mathrm{OH})$-stretching bands, and (3) the sum of the relative proportions of the six arrangements is unity. There are six arrangements and only three bands in the spectrum [due to arrangements (1), (2) and (4), (5)], and we cannot explicitly derive quantitative information on SRO. In addition, the bands due to richterite have different molar absorptivities than the bands due to tremolite (Hawthorne et al. 1997), and hence the intensities of the richterite and tremolite bands do not relate to the frequency of occurrence of local arrangements in the same way. Despite these problems, we can test a model for complete local disorder using the relative intensities of bands $\mathrm{A}$ and $\mathrm{B}$, as the arrangements involve coupling through $\mathrm{Na}$ at the $A$ site and hence have the same molar absorptivities.

Let $X$ be the proportion of richterite component [arrangement (1)], $(1-X)$ be the proportion of tremolite component, $x$ be the fraction of $\mathrm{F}\left[x=X_{\mathrm{F}}=\mathrm{F} /(\mathrm{OH}+\right.$ $\mathrm{F})], n_{\mathrm{i}}$ be the probability of occurrence of local arrangement (i) (i=1-6) such that $\Sigma n_{\mathrm{i}}=1$. Assuming no SRO, the probabilities of occurrence of these arrangements can be written as follows:

$$
\begin{aligned}
& \mathrm{n}_{1}=X(1-x)^{2} \\
& \mathrm{n}_{2}=2 X(1-X) x \\
& \mathrm{n}_{3}=X x^{2} \\
& \mathrm{n}_{4}=(1-X)(1-x)^{2} \\
& \mathrm{n}_{5}=2(1-X)(1-x) x \\
& \mathrm{n}_{6}=(1-X) x^{2} .
\end{aligned}
$$

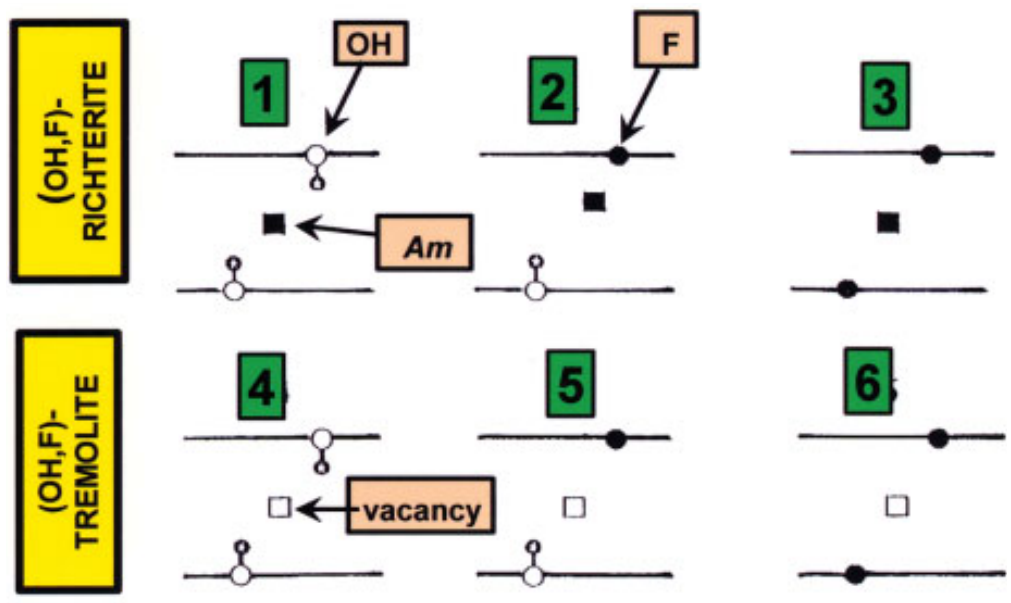

FIG. 16. Local arrangements in the $A$ cavity involving $(\mathrm{OH})$ and $\mathrm{F}$ : (a) $(\mathrm{OH}, \mathrm{F})$-bearing richterite, (b) $(\mathrm{OH}, \mathrm{F})$-bearing tremolite. White circles: $\mathrm{O}$ atoms of $(\mathrm{OH})$ groups, small black starred circles: $\mathrm{H}$ atoms, large black circles: $\mathrm{F}$ atoms, black square: $\mathrm{Na}$ at the $A(m)$ site, white square: vacant $A(m)$ site. Modified after Robert et al. (1999). 
The intensities of the individual bands should vary as follows:

$$
\begin{aligned}
& I_{\mathrm{A}} \propto 2 \mathrm{n}_{1}=2 X(1-x)^{2} \approx X(1-x) \\
& I_{\mathrm{B}} \propto \mathrm{n}_{2}=2 X(1-x) x \approx X x \\
& \left.\left.I_{\mathrm{C}} \propto 2 \mathrm{n}_{4}+\mathrm{n}_{5}=2\right) 1-X\right)(1-x)^{2}+ \\
& 2(1-X)(1-x) x \approx 1-X
\end{aligned}
$$

where the approximation assumes that the extinction coefficients of bands $\mathrm{A}, \mathrm{B}$ and $\mathrm{C}$ are equal [i.e., that the total band-intensity $I_{\mathrm{A}}+I_{\mathrm{B}}+I_{\mathrm{C}}$ is $\left.2(1-x)\right]$. The constituent arrangements for bands $\mathrm{A}$ and $\mathrm{B}$ have the same molar absorptivities, and hence we can test a model of complete local disorder using the intensities of the two bands. We do not know the value of $X$, but $X$ is not involved in the relative intensities of the A and $\mathrm{B}$ bands:

$$
\begin{aligned}
& I_{\mathrm{A}} /\left(I_{\mathrm{A}}+I_{\mathrm{B}}\right)=X(1-x) /[X(1-x)+ \\
& X x]=1-x \\
& I_{\mathrm{B}} /\left(I_{\mathrm{A}}+I_{\mathrm{B}}\right)=X x /[X(1-x)+X x]=x .
\end{aligned}
$$

In Figure 17, we compare the $\mathrm{F}$ content calculated from the observed intensity-ratios of the A and B bands with the F content determined by electron-microprobe analysis in richterite-fluororichterite solid-solutions. The agreement is in accord with complete short-range disorder of $(\mathrm{OH})$ and $\mathrm{F}$ in these amphiboles; there are no significant deviations from the 1:1 line.

The spectra discussed above indicate that $(\mathrm{OH})$ and $\mathrm{F}$ are short-range disordered. However, we must

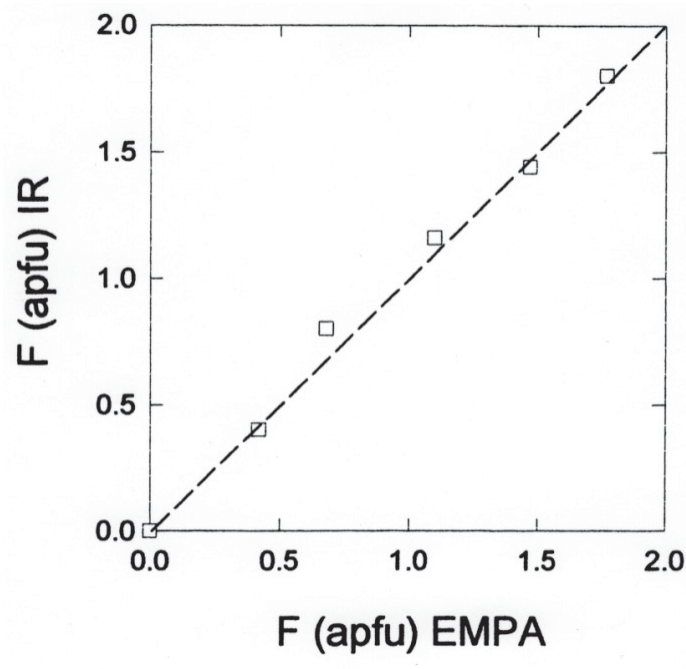

FIG. 17. Variation in F content calculated from the observed band-intensities for complete short-range disorder of $(\mathrm{OH})$ and $\mathrm{F}$ as a function of measured $\mathrm{F}$ content in richterite-fluororichterite solid-solutions. From Robert et al. (1999). emphasize that this disorder is with regard to each other (i.e., they are randomly disordered with regard to each other). Hawthorne et al. (1996a) showed that there are preferred arrangements of $\mathrm{Ca}$ and $\mathrm{Na}$ at the $M(4)$ site that couple to $\mathrm{OH}$ and $\mathrm{F}$ arrangements at the $\mathrm{O}(3)$ sites and $\mathrm{Na}$ at the $A(2)$ and $A(m)$ sites. Thus $(\mathrm{OH})$ and $\mathrm{F}$ may be randomly arranged with respect to each other, but they can also show SRO involving other atoms in the amphibole structure.

\section{Testing for SRO of $(\mathrm{OH})$ and $\mathrm{F}$ in pargasite}

Richterite, potassium-richterite and tremolite are characterized by the $M(1) M(1) M(3)$ arrangement $\mathrm{MgMgMg}$, and we examined the short-range behavior of $(\mathrm{OH})$ and $\mathrm{F}$ with respect to each other. The presence of the $M(1) M(1) M(3)$ arrangements $\mathrm{MgMgMg}$ and $\mathrm{MgMgAl}$ in pargasite (see above) allows us to test the potential for SRO of both $(\mathrm{OH})$ and $\mathrm{F}$ with respect to these $\mathrm{NN}$ arrangements.

Robert et al. (2000) examined the (OH,F) substitution in synthetic pargasite; the infrared spectra of these amphiboles are shown in Figure 18. As shown above, the spectrum of synthetic end-member pargasite consists of six bands, but Robert et al. (2000) fitted only three aggregate bands because the appearance of the spectra in Figure 18 make it seem that the principal changes relate to the $\mathrm{NN}$ arrangements $\mathrm{MgMgMg}$ and $\mathrm{MgMgAl}$ (and not to the NNN arrangements). The spectra of the F-bearing amphiboles were resolved into four bands; the $\mathrm{A}$ and $\mathrm{B}$ bands in F-free pargasite can also be identified in the spectra of the F-bearing pargasite, and it is notable that the intensity of the B band decreases considerably with increasing F content of the amphibole (Fig. 18). Moreover, the $\mathrm{A}^{\prime}$ and $\mathrm{B}^{\prime}$ bands increase rapidly with increasing $\mathrm{F}$, indicating that the associated arrangements involve $\mathrm{F}$, and that these bands are the result of two-mode behavior. The greater decrease in intensity of the $\mathrm{B}$ band $[\mathrm{MgMgAl}-\mathrm{OH}]$ relative to that of the A band $[\mathrm{MgMgMg}-\mathrm{OH}]$ indicates a relative decrease in the number of $\mathrm{MgMgAl}-\mathrm{OH}$ arrangements with increasing $\mathrm{F}$ content. There are two possibilities here: (1) F occurs preferentially at the $\mathrm{MgMgAl}$ arrangement; (2) Al is displaced to the $M(2)$ site by F occurring at $\mathrm{O}(3)$. Single-crystal structure refinement of fluoropargasite (Oberti et al. 1995c) shows all Al ordered at $M(2)$, indicating that mechanism (2) is operative in these amphiboles.

Della Ventura et al. (2001) examined amphiboles of nominal composition [richterite ${ }_{0.60}$ - pargasite $_{0.40}$ ] with varying amounts of $(\mathrm{OH})$ and $\mathrm{F}: \mathrm{Na}\left(\mathrm{Na}_{0.6} \mathrm{Ca}_{1.4}\right)$ $\left(\mathrm{Mg}_{4.6} \mathrm{Al}_{0.4}\right)\left(\mathrm{Si}_{7.2} \mathrm{Al}_{0.8}\right) \mathrm{O}_{22}(\mathrm{OH}, \mathrm{F})_{2}$. The infrared spectra are shown in Figure 19. Comparison of the spectra of end-member richterite (Fig. 19b) with that of F-bearing richterite (Fig. 19a) shows the addition of a new band in the latter at $3711 \mathrm{~cm}^{-1}$, a result of the new arrangement in which $\mathrm{F}$ replaces $(\mathrm{OH})$ at the $\mathrm{O}(3)$ site across the $A$ cavity (see above). The spectrum of 


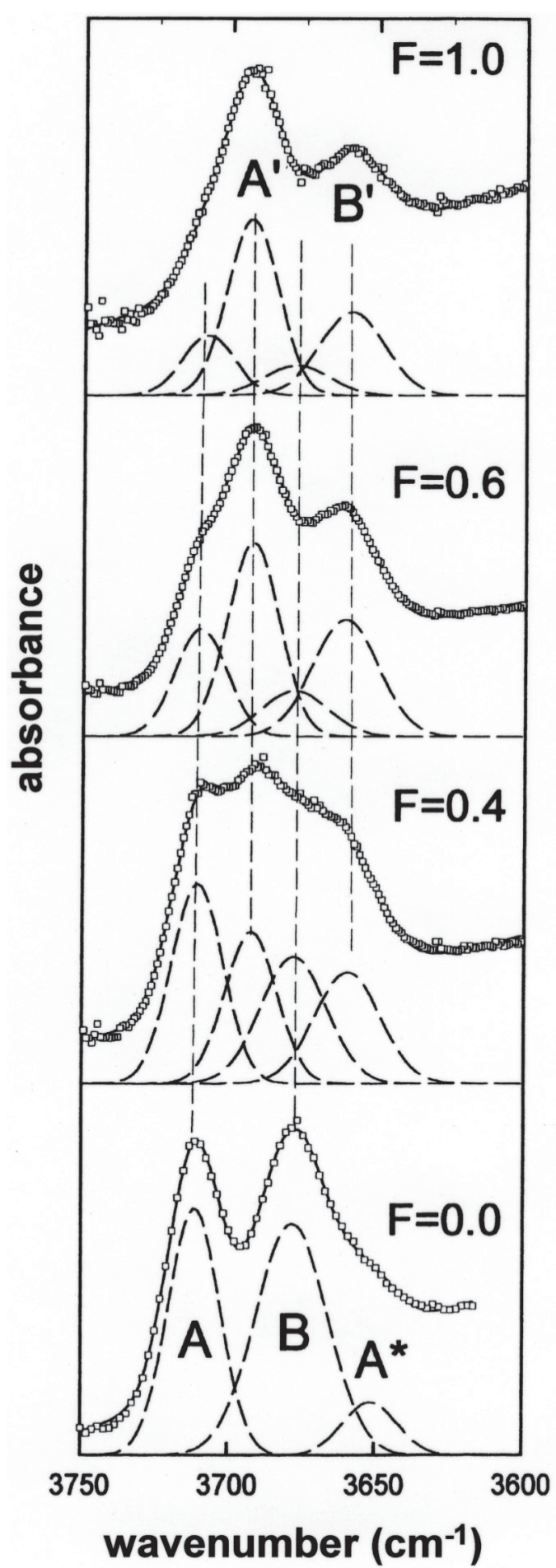

FIG. 18. Infrared spectra in the principal $(\mathrm{OH})$-stretching region for pargasite-fluoropargasite solid-solution. From Robert et al. (2000). end-member pargasite (Fig. 19e) has two (composite) bands, at 3710 and $3678 \mathrm{~cm}^{-1}$, and addition of $\mathrm{F}$ gives rise to two new bands, at 3694 and $3658 \mathrm{~cm}^{-1}$ (Fig. $19 \mathrm{~d}$, also see above). The spectrum of $\mathrm{Ri}_{0.60} \mathrm{~Pa}_{0.40}$ (Fig. 19c) shows a broad absorption at $3705 \mathrm{~cm}^{-1}$ and a weaker absorption at $3674 \mathrm{~cm}^{-1}$. Comparison with the other spectra of Figure 19 suggests that the 3705 $\mathrm{cm}^{-1}$ band corresponds to a combination of the 3711 $\mathrm{cm}^{-1}$ band in richterite [from the association of $(\mathrm{OH})$ and $\mathrm{F}$ at neighboring sites across the $A$ cavity], the

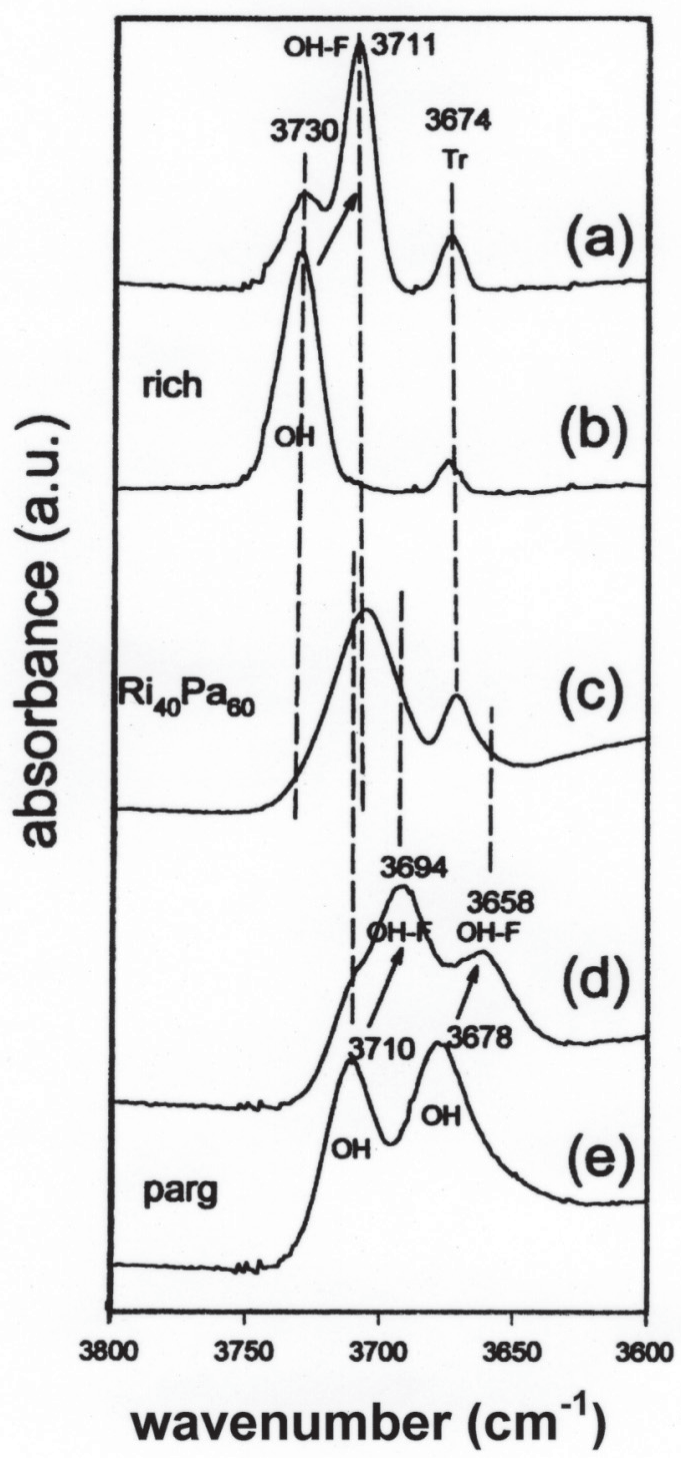

FIG. 19. Infrared spectra in the principal $(\mathrm{OH})$-stretching region for solid-solution $\mathrm{Ri}_{0.60} \mathrm{~Pa}_{0.40}(\mathrm{OH}, \mathrm{F})$ solid-solution. From Della Ventura et al. (2001). 


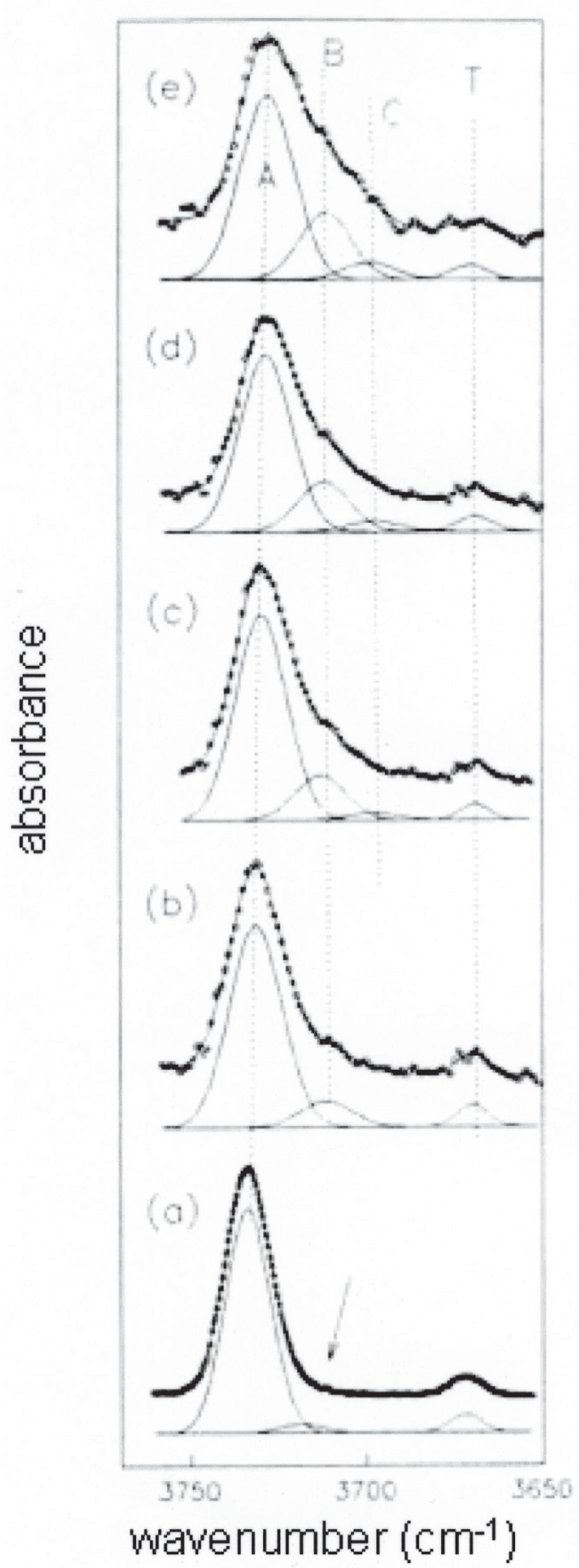

FIG. 20. Infrared spectra in the principal $(\mathrm{OH})$-stretching region for synthetic amphiboles along the join potassiumrichterite, $\mathrm{K} \mathrm{CaNa} \mathrm{Mg}_{5}\left(\mathrm{Si}_{7} \mathrm{Ti}^{4+}\right) \mathrm{O}_{22}(\mathrm{OH})_{2}$. From Della Ventura et al. (1996b).
$3710 \mathrm{~cm}^{-1}$ band in pargasite [from the arrangement $\mathrm{MgMgMg}-(\mathrm{OH})-(\mathrm{OH})]$, and the $3694 \mathrm{~cm}^{-1}$ band in pargasite [from the arrangement $\mathrm{MgMgMg}-(\mathrm{OH})-\mathrm{F}$ ]. The band due to the arrangement $\mathrm{MgMgAl}-(\mathrm{OH})-\mathrm{F}$ (at $3658 \mathrm{~cm}^{-1}$ ) and the $3730 \mathrm{~cm}^{-1}$ band in richterite are not present in the spectrum of $(\mathrm{OH}, \mathrm{F})$-bearing $\mathrm{Ri}_{0.60} \mathrm{~Pa}_{0.40}$. These spectra thus show that $\mathrm{F}$ completely replaces $(\mathrm{OH})$ in local $\mathrm{MgMgMg}-(\mathrm{OH})-\mathrm{Na}: \mathrm{SiSi}$ (richterite-like) arrangements, and partly replaces $(\mathrm{OH})$ groups in $\mathrm{MgMgMg}-(\mathrm{OH})-\mathrm{Na}: \mathrm{SiAl}$ (one of the pargasite-like arrangements). Note that in $\mathrm{MgMgAl}-(\mathrm{OH})$ : $\mathrm{SiAl}$ arrangements, F cannot replace $(\mathrm{OH})$, as is to be expected on bond-valence grounds: $\mathrm{MgMgAl}$ will provide incident bond-valence significantly greater than $1 v u$, and the $(\mathrm{OH})$ group can accommodate this because the $\mathrm{O}-\mathrm{H}$ bond can adjust its length to provide whatever bond valence is needed (i.e., 1.0-0.7vu). On the other hand, F needs to receive exactly $1 v u$ from its coordinating cations; there is no problem where these are $\mathrm{MgMgMg}(\sim 0.33 \times 3=1 v u)$, but where they are $\mathrm{MgMgAl}$, the resulting sum $(0.33+0.33+0.50=1.17$ $v u$ ) is too large to be accommodated by $\mathrm{F}$.

\section{SHORT-RANGE DisORDER OF $\mathrm{TI}^{4+}$ AND SI}

It has long been known that potassium-bearing richterite from lamproites in many cases shows $\mathrm{Si}+$ Al less than $8 a p f u$, and it was customary to assign Ti to the $T$-group cations to bring the total to 8 apfu (e.g., Papike et al. 1969, Wagner \& Velde 1986). Information from XAS (Mottana et al. 1990, Paris et al. 1993) and infrared spectroscopy (Della Ventura et al. 1991, 1993a) showed that $\mathrm{Ti}$ is indeed a tetrahedrally coordinated cation in Ti-bearing potassium-richterite. Site-scattering refinement and bond-length considerations in a series of Ti-bearing richterite crystals (Oberti et al.1992) showed that $\mathrm{Ti}^{4+}$ is a $T$-group cation and is completely ordered at the $T(2)$ site. However, the question now arises as to whether or not there is short-range order involving $\mathrm{Ti}^{4+}$ and $\mathrm{Si}$ at the $T(2)$ site. This issue was examined by Della Ventura et al. (1996b), who synthesized amphiboles along the join potassium-richterite $\left[\mathrm{K}(\mathrm{Ca} \mathrm{Na}) \mathrm{Mg}_{5} \mathrm{Si}_{8}\right.$ $\left.\mathrm{O}_{22}(\mathrm{OH})_{2}\right]-\mathrm{Ti}^{4+}$-bearing potassium-richterite $[\mathrm{K}(\mathrm{Ca}$ Na) $\left.\mathrm{Mg}_{5}\left(\mathrm{Si}_{7} \mathrm{Ti}^{4+}\right) \mathrm{O}_{22}(\mathrm{OH})_{2}\right]$ and characterized them by infrared spectroscopy. Their spectra are shown in Figure 20. There is prominent multi-mode behavior, and the spectra were fitted to four bands, A, B, C and $\mathrm{T}$; bands $\mathrm{A}, \mathrm{B}$ and $\mathrm{C}$ were assigned to $A$-site-full arrangements, and band $\mathrm{T}$ was assigned to the tremolite arrangement (see above). There is also a very weak band in the spectrum of Ti-free potassium-richterite (Fig. 20a) at $\sim 3720 \mathrm{~cm}^{-1}$; this is due to slight asymmetry in the band (which was fitted by a symmetrical Gaussian curve), and was ignored in the following arguments, as it is less than $5 \%$ of the total intensity. 


\section{Band assignment}

The occurrence of multi-mode behavior suggests the existence of distinct local arrangements, and the increase in intensity of the $\mathrm{B}$ and $\mathrm{C}$ bands with increasing $\mathrm{Ti}$ (Fig. 21) indicates that these local arrangements must involve $\mathrm{Ti}^{4+}$. There are two $T(2)$ sites in each ring of six tetrahedra (Fig. 3), and each of these may be occupied by $\mathrm{Si}$ or $\mathrm{Ti}^{4+}$. Thus there are only three possible $T(2)$ arrangements around each $(\mathrm{OH})$ group: $\mathrm{SiSi}, \mathrm{SiTi}^{4+}$ and $\mathrm{Ti}^{4+} \mathrm{Ti}^{4+}$. The intensity of an $(\mathrm{OH})$-stretching band is proportional to the number of $(\mathrm{OH})$ groups in each arrangement. Assuming a random distribution of $\mathrm{Si}$ and $\mathrm{Ti}^{4+}$ over the two sites, the probability of occurrence of each $T(2) T(2)$ pair as a function of bulk composition is as follows:

$$
\begin{array}{ll}
\text { SiSi: } & (1-\mathrm{x} / 4)^{2} \\
\mathrm{SiTi}^{4+}: & 2(1-\mathrm{x} / 4)(\mathrm{x} / 4) \\
\mathrm{Ti}^{4+} \mathrm{Ti}^{4+}: & (\mathrm{x} / 4)^{2}
\end{array}
$$

where $\mathrm{x}=\mathrm{Ti}^{4+}$ apfu. Figure 22 shows the observed relative intensities of the three resolved bands as a function of the calculated probabilities of occurrence of the three possible arrangements for a random distribution. There is close accord between the observed and calculated values, and this agreement leads us to assign the $\mathrm{B}$ band to the $\mathrm{SiTi}^{4+}$ arrangement and the $\mathrm{C}$ band to the $\mathrm{Ti}^{4+} \mathrm{Ti}^{4+}$ arrangement. The close agreement between the observed and calculated values indicates that there is complete short-range disorder of $\mathrm{Si}$ and $\mathrm{Ti}^{4+}$ over the $T(2)$ sites in the double chain of tetrahedra in the structure of potassium-richterite.

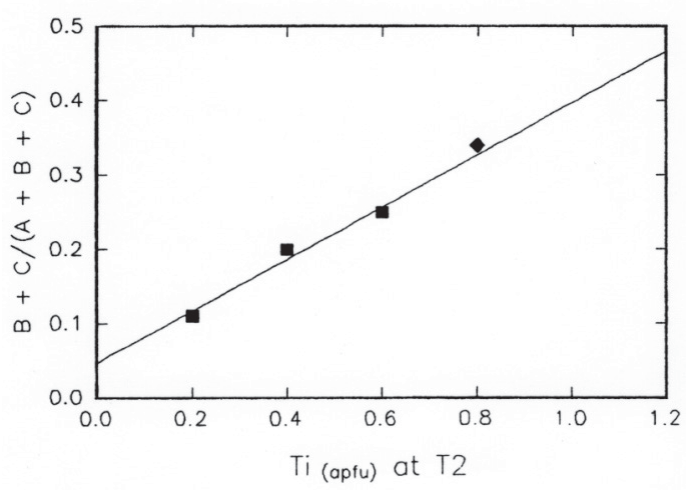

FIG. 21. The relative intensity of the $\mathrm{B}+\mathrm{C}$ bands in synthetic amphiboles along the join potassium-richterite, $\mathrm{K} \mathrm{CaNa}$ $\mathrm{Mg}_{5}\left(\mathrm{Si}_{7} \mathrm{Ti}^{4+}\right) \mathrm{O}_{22}(\mathrm{OH})_{2}$, as a function of Ti content. Modified from Della Ventura et al. (1996b).

\section{Local stereochemistry}

The $\mathrm{Ti}^{4+} \rightarrow$ Si substitution does not modify the charge distribution around the locally associated $(\mathrm{OH})$ groups, and hence the appearance of the lowerfrequency bands must be caused by the different local distortions of the six-membered rings of tetrahedra resulting from the different $T(2)$ arrangements: [ $\left.\mathrm{Si}_{6}\right]$, $\left[\mathrm{Si}_{5} \mathrm{Ti}^{4+}\right]$ and $\left[\mathrm{Si}_{4} \mathrm{Ti}^{4+}{ }_{2}\right]$. The $T(2)$ tetrahedron is invariably more distorted than the $T(1)$ tetrahedron in amphiboles, and this distortion increases with increasing $\mathrm{Ti}^{4+}$ occupancy of $T(2)$. Replacement of ${ }^{[4]} \mathrm{Si}^{4+}(\mathrm{r}=0.26$ $\AA)$ by ${ }^{[4]} \mathrm{Ti}^{4+}(\mathrm{r}=0.42 \AA$; Shannon 1976) must cause kinking of the double chain to preserve linkage with the strip of octahedra. This kinking will shorten the distance between the $\mathrm{H}$ atom of the $(\mathrm{OH})$ group and the $\mathrm{O}$ atoms coordinating the tetrahedra, inducing the appearance of the new $(\mathrm{OH})$-stretching bands.

\section{Short-RANGe Order of $\mathrm{TI}^{4+}$ AND $\mathrm{O}^{2-}$}

The association between $\mathrm{Ti}^{4+}$ and deficiency in monovalent anions has long been recognized in kaersutitic amphiboles (Leake 1968, Saxena \& Ekstrom 1970). However, the situation is complicated by the fact that dehydroxylation in amphiboles can proceed by oxidation of $\mathrm{Fe}^{2+}$ to $\mathrm{Fe}^{3+}$ (e.g., Barnes 1930, Addison et al. 1962, Ernst \& Wai 1970, Dyar et al. 1993, Popp et al. 1995), and hence other factors can affect the amount of monovalent anions in the amphibole structure. Sitescattering refinement with neutron-diffraction data (Kitamura \& Tokonami 1971, Kitamura et al. 1973,

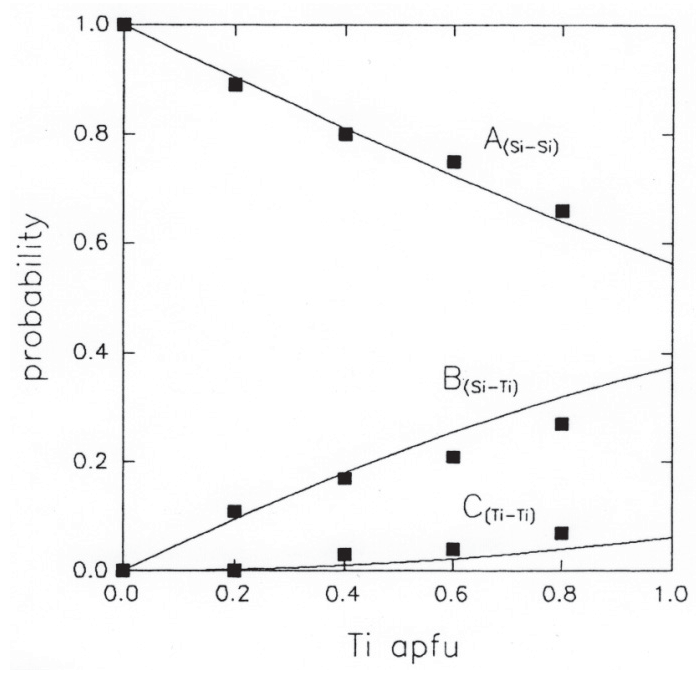

FIG. 22. Relative intensities of the A, B and C bands in synthetic amphiboles along the join potassium-richterite, $\mathrm{K}$ $\mathrm{CaNa} \mathrm{Mg}_{5}\left(\mathrm{Si}_{7} \mathrm{Ti}^{4+}\right) \mathrm{O}_{22}(\mathrm{OH})_{2}$, as a function of Ti content; the lines are calculated for equation (9) with a random distribution. From Della Ventura et al. (1996b). 


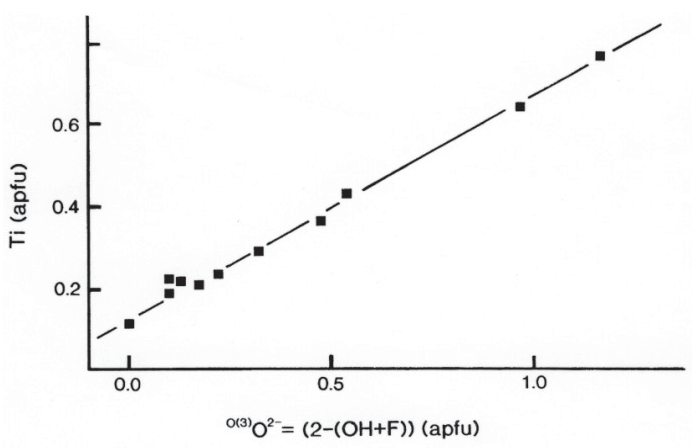

FIG. 23. Variation in $\mathrm{Ti}^{4+}$ as a function of the $\mathrm{O}^{2-}$ content of the $\mathrm{O}(3)$ site in amphiboles from Coyote Peak. From Hawthorne et al. (1998).

Kitamura \& Morimoto 1975, Jirak et al. 1986, Pechar et al. 1989) has shown that $\mathrm{Ti}$ is partly to completely ordered at the $M(1)$ site. The same conclusions have been made from crystal-structure refinement with Xrays, focusing on the stereochemistry of the $M(1)$ site. Hawthorne et al. (1998) showed that there is a very strong correlation between the $\mathrm{Ti}$ and $\mathrm{H}$ contents of a suite of sodic-calcic and sodic amphiboles from Coyote Peak, California (Fig. 23), where the H contents were determined by SIMS. The slope of the line in Figure 23 is in accord with the mechanism proposed by Oberti et al. (1992) for the incorporation of $\mathrm{Ti}^{4+}$ into the amphibole structure at the $M$ site(s):

$$
\begin{aligned}
& { }^{M(1)} \mathrm{Ti}^{4+}+2{ }^{\mathrm{O}(3)} \mathrm{O}^{2-} \rightarrow{ }^{M(1)}\left(\mathrm{Mg}, \mathrm{Fe}^{2+}\right)+ \\
& 2{ }^{\mathrm{O}(3)} \mathrm{OH}^{-}
\end{aligned}
$$

and the intercept at ${ }^{\mathrm{O}(3)} \mathrm{O}^{2-}=0$ implies a nearly constant $\mathrm{Ti}^{4+}$ content at the $M(2)$ site.

Oberti et al. (1992) proposed that the atoms involved in this mechanism are locally associated in the amphibole structure. This proposal makes sense from a local bond-valence perspective, as loss of a $\mathrm{H}$ atom from the coordination of $\mathrm{O}(3)$ necessitates incidence of considerable additional bond-valence from the locally coordinating cations. The association of a high-valence cation with the occurrence of a divalent anion at the $\mathrm{O}(3)$ site is a notable feature in amphiboles. In addition to kaersutite, there are three other amphiboles with dominant $\mathrm{O}^{2-}$ at the $\mathrm{O}(3)$ site (Table 5). Obertiite and dellaventuraite have $\mathrm{Ti}^{4+}$ as an essential constituent, and the local version of bond-valence theory indicates that there is a local association of $\mathrm{Ti}^{4+}$ at $M(1)$ with $\mathrm{O}^{2-}$ at $\mathrm{O}(3)$. For ungarettiite, the situation is somewhat different. Here, $\mathrm{Mn}^{3+}$ is ordered at the $M(1)$ and $M(3)$ sites; moreover, $\mathrm{Mn}^{3+}$ is a Jahn-Teller cation where in octahedral coordination, and it forms very short bonds to the $\mathrm{O}(3)$ site (Hawthorne et al. 1995), providing the necessary bond-valence for $\mathrm{O}^{2-}$ at the $\mathrm{O}(3)$ site.

\section{SUMMARY}

Extensive work in the last ten years has shown that short-range order-disorder is a common feature of synthetic amphiboles, and is present in natural amphiboles; indeed, SRO is probably an extremely common feature of natural amphiboles. The results described here also suggest that short-range order may be common in other rock-forming minerals such as micas and pyroxenes. To summarize the results on the amphiboles:

(1) LRO (Long-Range Order) involves the occurrence of atoms at different crystallographic sites in a structure such that average arrangement over all the unit cells in the crystal does not concur with that predicted by a random distribution;

(2) SRO (Short-Range Order) involves the formation of local clusters of atoms that occur either more or less frequently than predicted by a random local distribution.

(3) Infrared spectroscopy in the principal $\mathrm{OH}$ stretching region is particularly effective in characterizing local (short-range) arrangements of atoms in amphiboles.

(4) Extension of bond-valence theory to local arrangements (Hawthorne 1997) shows that short-range bond-valence requirements exert strong constraints on the local arrangements of atoms that can occur (i.e., that are stable).

(5) Infrared spectroscopy and bond-valence constraints show that local ordering of cations is very pronounced in a crystal of tremolite with significant $\mathrm{Na}$ and $\mathrm{Al}$ contents.

(6) The results mentioned in (5) show that the principal $\mathrm{OH}$-stretching frequency in amphiboles is affected by the cations at both nearest-neighbor and next-nearest-neighbor sites.

(7) A site-configuration symbol can be used to denote the sites affecting the principal $\mathrm{OH}$-stretching frequency in amphiboles: $M(1) M(1) M(3)-(\mathrm{OH})-A$ : $\mathrm{T}(1) T(1)-M(2) M(2) M(3)$; local arrangements of atoms can then be denoted by inserting the atoms at the relevant sites: e.g., $\mathrm{MgMgMg}-(\mathrm{OH})-\mathrm{Na}: \mathrm{SiAl}-\mathrm{MgMgMg}$ or $\mathrm{MgMgAl}-(\mathrm{OH})-\mathrm{Na}: \mathrm{SiAl}-\mathrm{MgMgAl}$.

(8) Synthesis, infrared spectroscopy and local bondvalence arguments show that monoclinic amphiboles

\begin{tabular}{|c|c|c|}
\hline Name & Formula & Ref. \\
\hline $\begin{array}{l}\text { Obertiite } \\
\text { Dellaventuraite } \\
\text { Ungarettite }\end{array}$ & 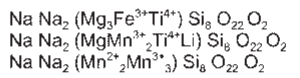 & $\begin{array}{l}\text { (1) } \\
\text { (2) } \\
\text { (3) }\end{array}$ \\
\hline
\end{tabular}
in the systems richterite-pargasite, tremolite-pargasite

References: (1) Hawthorne et al. (2000b), (2) Tait et al. (2004), (3) Hawthorne et al. (1995). 
and tremolite-hornblende show strong SRO involving $T$-, $C$ - and $A$-group cations.

(9) Synthesis and infrared spectroscopy for amphiboles with $(\mathrm{OH})-\mathrm{F}$ solid-solution show that amphiboles with $\square$ (vacancy) at the $A$ site (e.g., tremolite-fluorotremolite) show one-mode behavior, whereas amphiboles with $\mathrm{Na}$ or $\mathrm{K}$ at the $A$ site (e.g., richterite-fluororichterite) show two-mode behavior; it is apparent from this observation that nearest-neighbor arrangements of atoms couple through an occupied $A$ site, but do not couple through a vacant $A$ site.

(10) The relative band-intensities in $(\mathrm{OH})-\mathrm{F}$ amphibole solid-solutions showing two-mode behavior indicate that $(\mathrm{OH})$ and $\mathrm{F}$ are completely short-range disordered with respect to each other in the amphibole series examined thus far.

(11) Synthesis, infrared spectroscopy and local bondvalence arguments show that monoclinic amphiboles in the system pargasite-fluoropargasite show strong SRO of $(\mathrm{OH})$ and $\mathrm{F}$ with regard to the cations occupying the associated nearest-neighbor $M(1) M(1) M(3)$ sites: arrangements involving $\mathrm{MgMgAl}-(\mathrm{OH})$ are far more common than arrangements involving $\mathrm{MgMgAl}-\mathrm{F}$.

(12) Synthesis and infrared spectroscopy for Tibearing richteritic amphiboles show that ${ }^{[4]} \mathrm{Ti}^{4+}$ and $\mathrm{Si}$ are short-range disordered with regard to each other.

(13) Crystal-structure refinement, SIMS analysis and local bond-valence requirements suggest that ${ }^{[6]} \mathrm{Ti}^{4+}$ and ${ }^{\mathrm{O}(3)} \mathrm{O}^{2-}$ are locally associated at adjacent $M(1)$ and $\mathrm{O}(3)$ sites in dehydrogenated amphiboles.

(14) It is apparent from this review of recent results that SRO is very common in monoclinic amphiboles. Although much work remains to be done to fully characterize SRO across the complexities of amphibole composition-space, the general features are already emerging: local bond-valence requirements seem to be the principal factor controlling this type of order.

(15) SRO is of significance in that it will affect the stability of amphiboles (and other minerals in which it occurs) through its entropy (and enthalpy) effects; the way in which these effects can be formulated for such a complicated case is not yet clear, but what is clear is that future thermodynamic models need to consider $\mathrm{SRO}$ in amphiboles and probably in other minerals in which heterovalent substitutions are common.

\section{ACKNOWLEDGEMENTS}

We thank John Hughes and Mark Welch for their comments on this paper. This work was supported by the Natural Sciences and Engineering Research Council of Canada in the form of a Canada Research Chair in Crystallography and Mineralogy, Research Tools and Equipment, and Discovery Grants to FCH.

\section{REFERENCES}

Addison, C.C., Addison, W.E., Neal, G.H. \& Sharp, J.H (1962): Amphiboles. I. The oxidation of crocidolite. $J$. Chem. Soc., 1468-1471.

Armbruster, T., Oberhänsli, R., Bermanec, V. \& Dixon, R. (1993): Hennomartinite and kornite, two new $\mathrm{Mn}^{3+}$ rich silicates from the Wessels mine, Kalahari, South Africa. Schweiz. Mineral. Petrogr. Mitt. 73, 349-355.

BARNES, V.E. (1930): Changes in hornblende at about $800^{\circ}$ Am. Mineral. 15, 393-417.

Bocchio, R., Ungaretti, L. \& Rossi, G. (1978): Crystal chemical study of eclogitic amphiboles from Alpe Arami, Lepontine Alps, southern Switzerland. Soc. Ital. Mineral. Petrol., Rend. 34, 453-470.

BRown, I.D. (1981): The bond valence method. An empirical approach to chemical structure and bonding. In Structure and Bonding in Crystals II (M.O'Keeffe \& A. Navrotsky, eds.). Academic Press, New York, N.Y. (1-30).

Brown, I.D. (2002): The Chemical Bond in Inorganic Chemistry. The Bond Valence Model. Oxford University Press, Oxford, U.K.

BRown, I.D. \& AltermatT, D. (1985): Bond-valence parameters obtained from a systematic analysis of the inorganic crystal structure database. Acta Crystallogr. B41, 244 247.

Burdett, J.K. \& Hawthorne, F.C. (1993): An orbital approach to the theory of bond valence. Am. Mineral. 78, 884-892.

Chang, I.F. \& Mitra, S.S. (1968): Application of a modified random-element-isodisplacement model to long-wavelength optic phonons of mixed crystals. Phys. Rev. 172, 924-933.

Della Ventura, G., Hawthorne, F.C., Robert, J.-L., DelBove, F., Welch, M.F. \& Raudsepp, M. (1999): Shortrange order of cations in synthetic amphiboles along the richterite-pargasite join. Eur. J. Mineral. 11, 79-94.

Della Ventura, G., Hawthorne, F.C., Robert, J.-L. \& Iezzi, G. (2003): Synthesis and infrared spectroscopy of amphiboles along the tremolite-pargasite join. Eur. J. Mineral. 15, 341-347.

Della Ventura, G., Robert, J.-L. \& Bény, J.-M. (1991): Tetrahedrally coordinated $\mathrm{Ti}^{4+}$ in synthetic Ti-rich potassic richterite: evidence from XRD, FTIR , and Raman studies. Am. Mineral. 76, 1134-1140.

Della Ventura, G., Robert, J.-L., Bény, J.-M., Raudsepp, M. \& HawthorNE, F.C. (1993a): The OH-F substitution in Ti-rich potassium-richterites: Rietveld structure refinement and FTIR and micro-Raman spectroscopic studies of synthetic amphiboles in the system $\mathrm{K}_{2} \mathrm{O}-\mathrm{Na}_{2} \mathrm{O}-\mathrm{CaO}-\mathrm{MgO}-$ $\mathrm{SiO}_{2}-\mathrm{TiO}_{2}-\mathrm{H}_{2} \mathrm{O}-\mathrm{HF}$. Am. Mineral. 78, 980-987. 
Della Ventura, G., Robert, J.-L. \& Hawthorne, F.C. (1996a): Infrared spectroscopy of synthetic (Ni,Mg,Co)potassium-richterite. In Mineral Spectroscopy: a Tribute to Roger G. Burns (M.D. Dyar, C. McCammon \& M.W. Schaefer, eds.). Geochem. Soc., Spec. Publ. 5, 55-63.

Della Ventura, G., Robert, J.-L. \& Hawthorne, F.C. (1998b): Characterization of OH-F short-range order in potassium-fluor-richterite by infrared spectroscopy in the $\mathrm{OH}$-stretching region. Can. Mineral. 36, 181-185.

Della Ventura, G., Robert, J.-L., Hawthorne, F.C. \& Prost, R. (1996b): Short-range disorder of Si and Ti in the tetrahedral double-chain unit of synthetic Ti-bearing potassium-richterite. Am. Mineral. 81, 56-60.

Della Ventura, G., Robert, J.-L., Hawthorne, F.C., RaudSEPP, M. \& WELCH, M.D. (1998a): Contrasting patterns of ${ }^{[6]} \mathrm{Al}$ order in synthetic pargasite and Co-substituted pargasite. Can. Mineral. 36, 1237-1244.

Della Ventura, G., Robert, J.-L., Raudsepp, M. \& HaWTHORNE, F.C. (1993b): Site occupancies in monoclinic amphiboles: Rietveld structure refinement of synthetic nickel magnesium cobalt potassium richterite. Am. Mineral. 78, 633-640.

Della Ventura, G., Robert, J.-L., Sergent, J., Hawthorne, F.C. \& Delbove, F. (2001): Constraints on F vs. OH incorporation in synthetic ${ }^{[6]} \mathrm{Al}$-bearing in monoclinic amphiboles. Eur. J. Mineral. 13, 841-847.

Dyar, M.D., Mackwell, S.J., McGuire, A.V., Cross, L.R. \& RoberTSON, J.D. (1993): Crystal chemistry of $\mathrm{Fe}^{3+}$ and $\mathrm{H}^{+}$ in mantle kaersutite: implications for mantle metasomatism. Am. Mineral. 78, 968-979.

ERnST, W.G. \& WAI, C.M. (1970): Mössbauer, infrared, X-ray and optical study of cation ordering and dehydrogenation in natural and heat-treated sodic amphiboles Am. Mineral. 55, 1226-1258.

Gottschalk, M., Andrut, M. \& Melzer, S. (1999): The determination of the cummingtonite content of synthetic tremolite. Eur. J. Mineral. 11, 967-982.

HANISCH, K. (1966): Messung des Ultrarot-Pleochroismus von Mineralen. VI. Der Pleochroismus des OH-Streckfrequenz in Riebeckit. Neues Jahrb. Mineral., Monatsh., 109-112.

HAWTHORNE, F.C. (1983): The crystal chemistry of the amphiboles. Can. Mineral. 21, 173-480.

HAWTHORNe, F.C. (1997): Short-range order in amphiboles: a bond-valence approach. Can. Mineral. 35, 201-216.

Hawthorne, F.C., Cooper, M.A., Grice, J.D. \& Ottolini, L. (2000b): A new anhydrous amphibole from the Eifel region, Germany: description and crystal structure of obertiite, $\mathrm{NaNa}_{2}\left(\mathrm{Mg}_{3} \mathrm{Fe}^{3+} \mathrm{Ti}^{4+}\right) \mathrm{Si}_{8} \mathrm{O}_{22} \mathrm{O}_{2}$. Am. Mineral. $\mathbf{8 5}, 236-241$
Hawthorne, F.C., Della Ventura, G. \& Robert, J.-L. (1996c): Short-range order of $(\mathrm{Na}, \mathrm{K})$ and $\mathrm{Al}$ in tremolite: an infrared study. Am. Mineral. 81, 782-784.

Hawthorne, F.C., Della Ventura, G. \& Robert, J.-L. (1996d): Short-range order and long-range order in amphiboles: a model for the interpretation of infrared spectra in the principal $\mathrm{OH}$-stretching region. In Mineral Spectroscopy: a Tribute to Roger G. Burns (M.D. Dyar, C. McCammon \& M.W. Schaefer, eds.). Geochem. Soc., Spec. Publ. 5, 49-54.

Hawthorne, F.C. \& GRundy, H.D. (1973a): The crystal chemistry of the amphiboles. I. Refinement of the crystal structure of ferrotschermakite. Mineral. Mag. 39, 36-48.

Hawthorne, F.C. \& GRundy, H.D. (1973b): The crystal chemistry of the amphiboles. II. Refinement of the crystal structure of oxykaersutite. Mineral. Mag. 39, 390-400.

HaWTHORNE, F.C. \& GRUNDY, H.D. (1976): The crystal chemistry of the amphiboles. IV. X-ray and neutron refinements of the crystal structure of tremolite. Can. Mineral. 14, 334-345.

Hawthorne, F.C., Oberti, R., Cannillo, E., Sardone, N., ZanetTi, A., Grice, J.D. \& Ashley, P.M. (1995): A new anhydrous amphibole from the Hoskins mine, Grenfell, New South Wales, Australia: description and crystal structure of ungarettiite, $\mathrm{NaNa}_{2}\left(\mathrm{Mn}^{2+}{ }_{2} \mathrm{Mn}^{3+}{ }_{2}\right) \mathrm{Si}_{8} \mathrm{O}_{22} \mathrm{O}_{2}$. Am. Mineral. 80, 165-172.

Hawthorne, F.C., Oberti, R., Ottolini, L. \& Foord, E.E. (1996b): Lithium-bearing fluor-arfvedsonite from Hurricane Mountain, New Hampshire: a crystal-chemical study. Can. Mineral. 34, 1015-1019.

HaWthorne, F.C., OberTi, R. \& SARDONE, N. (1996a): Sodium at the A site in clinoamphiboles: the effects of composition on patterns of order. Can. Mineral. 34, 577-593.

Hawthorne, F.C., Oberti, R., Ungaretti, L. \& Grice, J.D. (1992): Leakeite, $\mathrm{NaNa}_{2}\left(\mathrm{Mg}_{2} \mathrm{Fe}^{3+}{ }_{2} \mathrm{Li}\right) \mathrm{Si}_{8} \mathrm{O}_{22}(\mathrm{OH})_{2}$, a new alkali amphibole from the Kajlidongri manganese mine, Jhabua district, Madhya Pradesh, India. Am. Mineral. 77, 1112-1115.

Hawthorne, F.C., Oberti, R., Ungaretti, L. \& Grice, J.D. (1996e): A new hyper-calcic amphibole with $\mathrm{Ca}$ at the A site: fluor-cannilloite from Pargas, Finland. Am. Mineral. 81, 995-1002.

Hawthorne, F.C., Oberti, R., Ungaretti, L., Welch, M.F., RAUDSEPP, M. \& JENKINS, D.M. (1997): A Rietveld and infrared study of synthetic amphiboles along the potassium-richterite - tremolite join. Am. Mineral. 82, 708716.

Hawthorne, F.C., Oberti, R., Zanetti, A. \& Czamanske, G.K. (1998): The role of Ti in hydrogen-deficient amphiboles: sodic-calcic and sodic amphiboles from Coyote Peak, California. Can. Mineral. 36, 1253-1265. 
Hawthorne, F.C., Ungaretti, L., Oberti, R., Bottazzi, P. \& CZAMANSKe, G.K. (1993): Li: an important component in igneous alkali amphiboles. Am. Mineral. 78, 733-745.

Hawthorne, F.C., Ungaretti, L., Oberti, R., CAnnillo, E. \& SMELIK, E.A. (1994): The mechanism of ${ }^{[6]} \mathrm{Li}$ incorporation in amphiboles. Am. Mineral. 79, 443-451.

HawthoRne, F.C. \& WaychunAs, G.A. (1988): Spectrum fitting methods. In Spectroscopic Methods in Mineralogy and Geology (F.C. Hawthorne, ed.). Rev. Mineral. 18, 63-98.

Hawthorne, F.C., Welch, M.D., Della Ventura, G., Liu, S., RoBERT, J.-L. \& JENKINS, D.M. (2000a): Short-range order in synthetic aluminous tremolites: an infrared and triplequantum MAS NMR study. Am. Mineral. 85, 1716-1724.

Jenkins, D.M., Sherriff, B.L., Cramer, J. \& Xu, Z. (1997): $\mathrm{Al}, \mathrm{Si}$, and $\mathrm{Mg}$ occupancies in tetrahedrally and octahedrally coordinated sites in synthetic aluminous tremolite. Am. Mineral. 82, 280-290.

Jirak, Z., Pechar, F. \& VRatislav, S. (1986): Distribution of cations and the proton location in kaersutite. Cryst. Res. Technol. 21, 1517-1519.

Kitamura, M. \& ToKonami, M. (1971): The crystal structure of kaersutite. Sci. Rep Tohoku Univ., Ser. 3 11, 125-141.

Kitamura, M., Tokonami, M., Koto, K., Horiuchi, H. \& Morimoto, N. (1973): Cation ordering in kaersutite by neutron diffraction. Mineral. Soc. Japan. J. 11, 49.

Kitamura, M. \& Tokonami, M. \& Morimoto, N. (1975): Distribution of titanium atoms in oxy-kaersutite. Contrib. Mineral. Petrol. 51, 167-172.

LAW, A.D. (1976): A model for the investigation of hydroxyl spectra of amphiboles. In The Physics and Chemistry of Minerals and Rocks (R.G.J. Strens, ed.). J. Wiley \& Sons, London, U.K.

LEAKE, B.E. (1968): A catalog of analyzed calciferous and subcalciferous amphiboles together with their nomenclature and associated minerals. Geol. Soc. Am., Spec. Pap. 98.

Mottana, A., Paris, E., Della Ventura, G. \& Robert, J.-L. (1990): Spectroscopic evidence for tetrahedrally-coordinated titanium in richteritic amphiboles. Rend. Fis. Accad. Lincei 1, 387-392.

Oberti, R., Camara, F., Ottolini, L. \& Caballero, J.M. (2003): Lithium in amphiboles: detection, quantification, and incorporation mechanisms in the compositional space bridging sodic and ${ }^{\mathrm{B}} \mathrm{Li}$-amphiboles. Eur. J. Mineral. 15, 309-319.

Oberti, R., Hawthorne, F.C., Ungaretti, L. \& Cannillo, E. (1995b): ${ }^{[6]} \mathrm{Al}$ disorder in amphiboles from mantle peridotites. Can. Mineral. 33, 867-878.

Oberti, R., SARdone, N., Hawthorne, F.C., RAudsepp, M. \& TURNOCK, A.C. (1995c): Synthesis and crystal-structure refinement of synthetic fluor-pargasite. Can. Mineral. 33, 25-31.

Oberti, R., Ungaretti, L., Cannillo, E. \& Hawthorne, F.C. (1992): The behaviour of Ti in amphiboles. I. Four- and sixcoordinate Ti in richterite. Eur. J. Mineral. 3, 425-439.

Oberti, R., Ungaretti, L., Cannillo, E., Hawthorne, F.C. \& Memmi, I. (1995a): Temperature-dependent Al order-disorder in the tetrahedral double-chain of $C 2 / \mathrm{m}$ amphiboles. Eur. J. Mineral. 7, 1049-1063.

PAPIKe, J.J., Ross, M. \& Clark, J.R. (1969): Crystal-chemical characterization of clinoamphiboles based on five new structure refinements. Mineral. Soc. Am., Spec. Pap. 2, 117-136.

Paris, E., Mottana, A., Della Ventura, G. \& Robert, J.-L. (1993): Titanium valence and coordination in synthetic richterite-Ti-richterite amphiboles: a synchrotron-radiation XAS study. Eur. J. Mineral. 5, 455-464.

PAuling, L. (1929): The principles determining the structures of complex ionic crystals. J. Am. Chem. Soc. 51, 10101026.

Pechar, F., Fuess, H. \& Joswig, W. (1989): Refinement of the crystal structure of kaersutite (Vlčí Hora, Bohemia) from neutron diffraction. Neues Jahrb. Mineral., Monatsh., 137-143.

Phillips, M.W., Draheim, J.E., Popp, R.K., Clowe, C.A. \& PinKerton, A.A. (1989): Structural investigation of oxidation-dehydrogenation effects in tschermakitic hornblende. Am. Mineral. 74, 764-773.

Phillips, M.W., PopP, R.K. \& Clowe, C.A. (1988): Structural adjustments accompanying oxidation-dehydrogenation in amphiboles. Am. Mineral. 73, 500-506.

Popp, R.K., Virgo, D. \& Phillips, M. (1995): H deficiency in kaersutitic amphiboles: experimental verification. Am. Mineral. 80, 1347-1350.

Preiser, C., Lösel, J., Brown, I.D., KunZ, M. \& Skowron, A. (1999): Long range Coulomb forces and localized bonds. Acta Crystallogr. B55, 698-711.

Raudsepp, M., Turnock, A.C., Hawthorne, F.C. (1991): Amphiboles synthesis at low pressure: what grows and what doesn't. Eur. J. Mineral. 3, 983-1004.

Raudsepp, M., Turnock, A.C., Hawthorne, F.C., SherrifF, B.L. \& HaRTMAN, J.S. (1987): Characterization of synthetic pargasitic amphiboles $\left(\mathrm{NaCa}_{2} \mathrm{Mg}_{4} \mathrm{M}^{3+} \mathrm{Si}_{6} \mathrm{Al}_{2} \mathrm{O}_{22} \mathrm{O}\right.$ $\mathrm{H}, \mathrm{F})_{2} ; \mathrm{M}^{3+}=\mathrm{Al}, \mathrm{Cr}, \mathrm{Ga}, \mathrm{Sc}, \mathrm{In}$ ) by infrared spectroscopy, Rietveld structure refinement and ${ }^{27} \mathrm{Al},{ }^{29} \mathrm{Si}$, and ${ }^{19} \mathrm{~F}$ MAS NMR spectroscopy. Am. Mineral. 72, 580-593.

Redhammer, G.J., Beran, A., Schneider, J., Amthauer, G. \& LOTTERMOSER, W. (2000): Spectroscopic and structural properties of synthetic micas on the annite-siderophyllite binary: synthesis, crystal structure refinement, Mössbauer, and infrared spectroscopy. Am. Mineral. 85, 449-465. 
Robert, J.-L., Della Ventura, G. \& Hawthorne, F.C. (1999): Near-infrared study of short-range disorder of $\mathrm{OH}$ and $\mathrm{F}$ in monoclinic amphiboles. Am. Mineral. 84, 86-91.

Robert, J.-L., Della Ventura, G., Welch, M.D. \& HaWTHORNE, F.C. (2000): The OH-F substitution in synthetic pargasite at $1.5 \mathrm{kbar}, 850^{\circ} \mathrm{C}$. Am. Mineral. 85, 926-931.

Robinson, K., Gibbs, G.V., Ribbe, P.H. \& Hall, M.R. (1973): Cation distribution in three hornblendes. Am. J. Sci. 273A, $522-535$.

SAXENA, S.K. \& Ekstrom, T.K. (1970): Statistical chemistry of calcic amphiboles. Contrib. Mineral. Petrol. 26, 276284.

Semet, M.P. (1973): A crystal-chemical study of synthetic magnesiohastingsite. Am. Mineral. 58, 480-494.

SHANNON, R.D. (1976): Revised effective ionic radii and systematic studies of interatomic distances in halides and chalcogenides. Acta Crystallogr. A32, 751-767.

Skogby, H. \& Rossman, G.R. (1991): The intensity of amphibole $\mathrm{OH}$ bands in the infrared absorption spectrum. Phys. Chem. Minerals 18, 64-68.

StRENS, R.G.J. (1966): Infrared study of cation ordering and clustering in some (Fe, $\mathrm{Mg}$ ) amphibole solid solutions. Chem. Comm. (Chem. Soc. London) 15, 519-520.
STRENS, R.G.J. (1974): The common chain, ribbon and ring silicates. In The Infrared Spectra of Minerals (V.C. Farmer, ed.). Mineralogical Society, London, U.K.

Tait, K.T., Hawthorne, F.C., Grice, J.D., Ottolini, L. \& NAYAK, V.K. (2004): Dellaventuraite, $\mathrm{NaNa}_{2}\left(\mathrm{MgMn}^{3+}{ }_{2} \mathrm{Ti}^{4+}\right.$ Li) $\mathrm{Si}_{8} \mathrm{O}_{22} \mathrm{O}_{2}$, a new anhydrous amphibole from the Kajlidongri manganese mine, Jhabua District, Madhya Pradesh, India. Am. Mineral. 90, 304-309.

Tiepolo, M., Zanetti, A. \& Oberti, R. (1999): Detection, crystal-chemical mechanisms and petrological implications of ${ }^{[6]} \mathrm{Ti}^{4+}$ partitioning in pargasite and kaersutite. Eur. J. Mineral. 11, 345-354.

WAGNER, C. \& Velde, D. (1986): The mineralogy of K-richterite bearing lamproites. Am. Mineral. 71, 17-37.

Welch, M.D., KolodzIeJSKi, W. \& KLINOwsKi, J. (1994): A multinuclear NMR study of synthetic pargasaite. Am. Mineral. 79, 261-268.

Welch, M.D., Lu, S. \& KLINOWSKI, J. (1998): ${ }^{29}$ Si MAS NMR systematics of calcic and sodic-calcic amphiboles. Am. Mineral. 83, 85-96.

Received November 30, 2004, revised manuscript accepted July 15, 2005. 